\title{
How anthropogenic changes may affect soil-borne parasite diversity? Plant-parasitic nematode communities associated with olive trees in Morocco as a case study
}

\author{
Nadine Ali ${ }^{1,2^{*}}$, Johannes Tavoillot ${ }^{2}$, Guillaume Besnard ${ }^{3}$, Bouchaib Khadari ${ }^{4}$, Ewa Dmowska ${ }^{5}$, \\ Grażyna Winiszewska ${ }^{5}$, Odile Fossati-Gaschignard ${ }^{2}$, Mohammed Ater ${ }^{6}$, Mohamed Aït Hamza ${ }^{7}$, \\ Abdelhamid El Mousadik ${ }^{7}$ Aïcha El Oualkadi ${ }^{8}$, Abdelmajid Moukhli ${ }^{8}$, Laila Essalouh ${ }^{4}$, Ahmed El Bakkali ${ }^{9}$, \\ Elodie Chapuis $2,10,11+$ and Thierry Mateille $e^{2 \dagger}$
}

\begin{abstract}
Background: Plant-parasitic nematodes (PPN) are major crop pests. On olive (Olea europaea), they significantly contribute to economic losses in the top-ten olive producing countries in the world especially in nurseries and under cropping intensification. The diversity and the structure of PPN communities respond to environmental and anthropogenic forces. The olive tree is a good host plant model to understand the impact of such forces on PPN diversity since it grows according to different modalities (wild, feral and cultivated olives). A wide soil survey was conducted in several olive-growing regions in Morocco. The taxonomical and the functional diversity as well as the structures of PPN communities were described and then compared between non-cultivated (wild and feral forms) and cultivated (traditional and high-density olive cultivation) olives.

Results: A high diversity of PPN with the detection of 117 species and 47 genera was revealed. Some taxa were recorded for the first time on olive trees worldwide and new species were also identified. Anthropogenic factors (wild vs cultivated conditions) strongly impacted the PPN diversity and the functional composition of communities because the species richness, the local diversity and the evenness of communities significantly decreased and the abundance of nematodes significantly increased in high-density conditions. Furthermore, these conditions exhibited many more obligate and colonizer PPN and less persister PPN compared to non-cultivated conditions. Taxonomical structures of communities were also impacted: genera such as Xiphinema spp. and Heterodera spp. were dominant in wild olive, whereas harmful taxa such as Meloidogyne spp. were especially enhanced in high-density orchards.

Conclusions: Olive anthropogenic practices reduce the PPN diversity in communities and lead to changes of the community structures with the development of some damaging nematodes. The study underlined the PPN diversity as a relevant indicator to assess community pathogenicity. That could be taken into account in order to design control strategies based on community rearrangements and interactions between species instead of reducing the most pathogenic species.
\end{abstract}

Keywords: Anthropisation, Communities, Functional diversity, Morocco, Olive, Plant-parasitic nematodes, Taxonomical structures

\footnotetext{
*Correspondence: nadineali.tichrine.univ@gmail.com

${ }^{\dagger}$ Elodie Chapuis and Thierry Mateille are co-leaders of the publication

1 Plant Protection Department, Faculty of Agriculture, Tishreen University,

PO Box 2233, Latakia, Syrian Arab Republic

Full list of author information is available at the end of the article
} 


\section{Background}

A biological community refers to an assemblage of populations from different organisms living together in a habitat. This biological assemblage within a community could be described by several traits such as the number of species (richness), their relative abundance (evenness), the present species (taxonomical structure), the interactions among them as well as their temporal and spatial variation [1]. Species diversity is important for the stability of the community and consequently that of the ecosystems [2]. For instance, functional consequences on ecosystem processes are related to species richness and to speciesspecific traits. Moreover, species diversity can play a crucial role in ecosystems resilience and/or resistance to human disturbances and to environmental changes [1].

Soil communities have been described as the "poor man's tropical rainforest", because of the relatively high level of biodiversity and the large proportion of undescribed species, as well as the limited information available about their community structure and dynamics [3]. Human interventions in ecosystems such as land-use changes, invasive species and over-exploitation, lead to biodiversity loss and/or species extinction [4]. For example, in agrosystems, crop intensification greatly disturbs the soils, affecting composition and functions of their biota [5, 6].

Among soil biota, nematodes are ubiquitous soil inhabitants and among the most abundant and diversified biota [7]. They reflect several feeding behaviors that make it possible to allocate them to different trophic groups: bacterivores, fungivores, carnivores and plant feeders [8]. Due to the various life strategies of nematodes ( $r$ and $K$ for colonizer and persister nematodes, respectively), their diversity and their co-existence in communities are closely related to short response time, to environmental changes and to disturbances in their habitats [9].

Plant-parasitic nematodes (PPN) are known to attack a wide range of crop plants (cereals, vegetables, tubers, fruits, flowers, etc.), causing annual crop losses estimated at billions of dollars in worldwide [10, 11]. On the olive tree (Olea europaea L.), PPN are able to reduce tree growth [12] and may be responsible for $5-10 \%$ yield losses [13]. Their impact is especially strengthened in nurseries and in intensive cultivation systems where irrigation conditions favor the development of roots and, as a result, nematode multiplication [14]. A high diversity of PPN on olive trees was reviewed worldwide $[14,15]$.

In Morocco, olive tree is a good example of ecological, botanical and genetic diversity. Spontaneous trees are distinguished under three different forms: (i) autochthonous wild trees, usually referred to as oleasters $(O$. europaea subsp. europaea var. sylvestris (Mill.) Lehr.), are common in coastal and mountainous regions [16]; (ii) the
Moroccan hexaploid olive subspecies O. europaea subsp. maroccana is endemic in the High Atlas Mountains [17]; (iii) feral forms are wild-looking olive trees that correspond either to abandoned cultivated olive trees or to olive trees grown from cultivated olive seeds spread by birds. Additionally, cultivated forms (O. europaea subsp. europaea var. europaea) are also widespread. Different olive cropping systems can be distinguished according to tree density [18]: traditional orchards (ca. 80-400 trees/ ha) vs high-density orchards (up to 1800 trees/ha). However, these new intensive techniques, accompanied by the replacement of traditional low-intensive production with highly intensified and mechanized cultivation, including the use of herbicides to remove weeds, are expected to induce a possible degradation of the plant communities and their associated fauna [19]. As for olive propagation, it is generally performed from root cuttings that could be accompanied by soil transport and, consequently, by the spread of soil-borne parasites. Thus, PPN could be spread by soil transport or by unsanitized plant material (e.g. from uncertified nurseries). The local PPN populations in olive-growing areas could therefore have originated from historical mixtures made up of native (before olive introduction) and invasive (with root stocks from oleasters) communities. In this context, we hypothesize that PPN communities may have adapted to olive propagation processes and to cultivation practices. These anthropogenic forces could exist in Morocco where high-density cultivated areas have been extended and where ancestral or traditional cultivars have often been discarded in favor of a few highly productive varieties [20]. These new conditions of cultivation might have to face a resurgence of several pests, including PPN. To address these hypotheses, this study was undertaken in order to: (i) describe the species diversity of PPN communities associated with wild, feral and cultivated olives in Morocco where their diversity is completely unknown, and (ii) assess how anthropogenic forces (propagation and intensification practices) could impact the diversity and the structure of PPN communities by comparing them between different olive growing modalities.

\section{Methods}

\section{Site description}

Sampling of soil and olive leaves took place in Morocco from March to April 2012. Wild olive locations were as far as possible from current orchards. In contrast, feral olive locations were sampled within the proximity of cultivated olive stands or near main roads. The survey was conducted at 94 sites in several geographic regions all along a northeast-southwest $900-\mathrm{km}$ long transect (Fig. 1; Table 1). The main regions sampled included: (i) the Souss region (15 sites), located on the southern side 


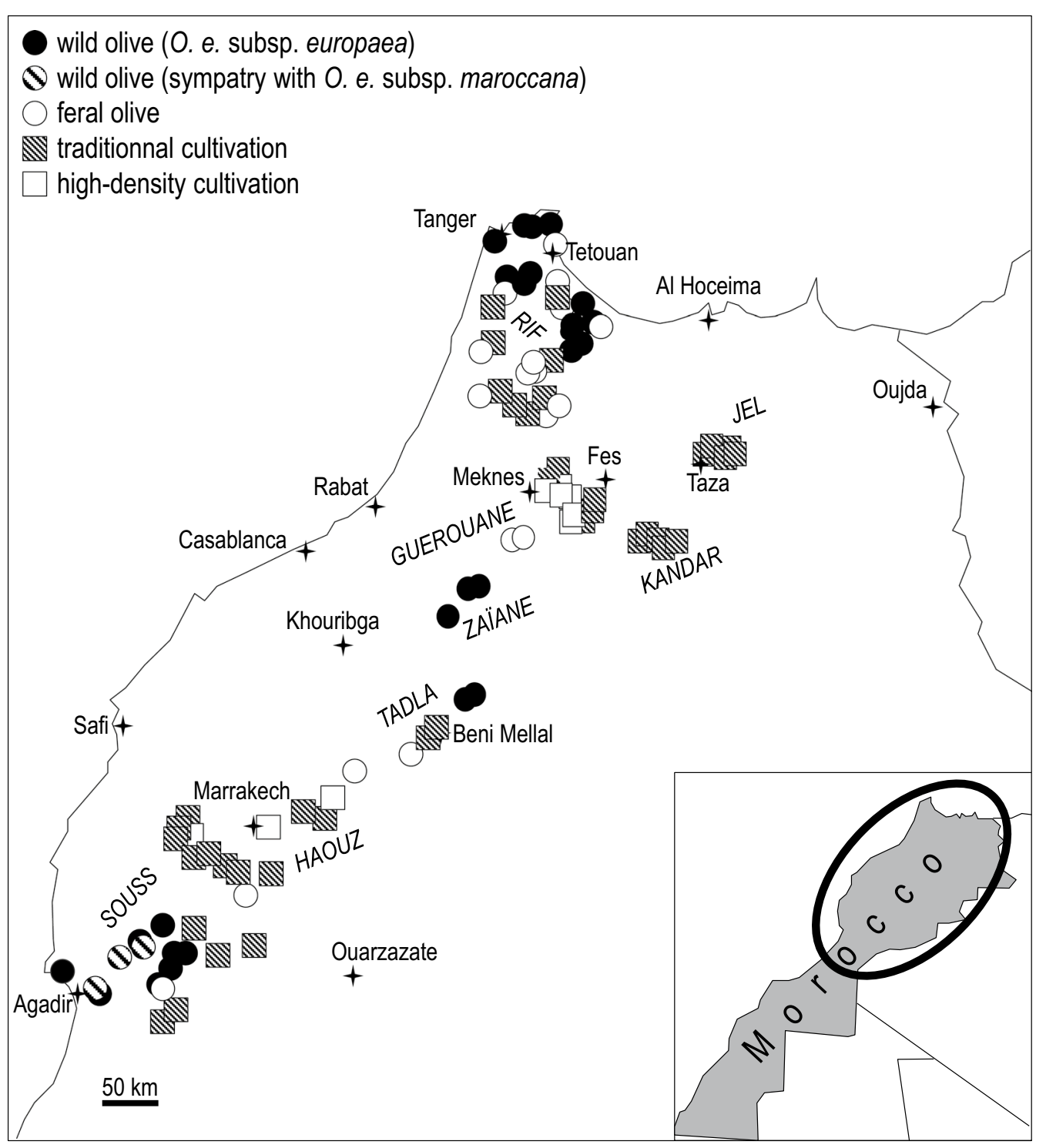

Fig. 1 Sites sampled in Morocco. Olive-growing modalities are given for each site

of the High Atlas Mountains near Agadir, where sampled trees were either wild (including trees of O. europaea maroccana in sympatry with O. europaea var. sylvestris), feral, or traditionally cultivated; (ii) the Haouz region (15 sites) located on the northern side of the High Atlas Mountains near Marrakech, where sampled trees were traditionally or high-density cultivated, or feral; (iii) the Tadla region (five sites) located along the northern side of the southern Middle Atlas Mountains near Beni Mellal, where sampled trees were either wild, feral, or traditionally cultivated; (iv) the Zaïane region (three wild olive sites), south of Meknes; (v) the Guerouane region (with traditionally or high-density cultivated sampled trees, and less feral trees); (vi) the Kandar region (five sites) located in the northern Middle Atlas Mountains, south of Fes and the Jel plain situated to the east of Taza in eastern Morocco (five sites), where trees are traditionally cultivated; and (vii) both the Atlantic and Mediterranean slopes of the Rif mountains in the north (33 sites) where most of the sampled trees were wild or feral, and less traditionally cultivated.

\section{Soil sampling}

Considering that PPN spend all or almost all their life in the soil [21], the nematode sampling only included soil. A total of 213 samples were collected from the 94 sites. 
Table 1 Location of the olive sampling sites surveyed in Morocco

\begin{tabular}{|c|c|c|c|c|c|}
\hline Geographic region & City & Olive modality & No of sites & $\begin{array}{l}\text { Latitude N } \\
\left.\text { (decimal }^{\circ}\right)\end{array}$ & $\begin{array}{l}\text { Longitude W } \\
\text { (decimal }^{\circ} \text { ) }\end{array}$ \\
\hline \multirow[t]{9}{*}{ Souss } & Tiguert & Wild & 2 & 30.63 & 9.86 \\
\hline & Aourir & Wild & 1 & 30.52 & 9.59 \\
\hline & Ouled Teïma & Wild & 1 & 30.81 & 9.14 \\
\hline & & Feral & 1 & 30.42 & 9.02 \\
\hline & & Traditional cultivation & 1 & 30.42 & 9.02 \\
\hline & Taroudant & Wild & 4 & 30.74 & 8.77 \\
\hline & & Traditional cultivation & 2 & 30.61 & 9.34 \\
\hline & Ouled Berhil & Traditional cultivation & 1 & 30.65 & 8.18 \\
\hline & Aoulouz & Traditional cultivation & 1 & 30.55 & 8.66 \\
\hline \multirow[t]{8}{*}{ Haouz } & El Kelaa Des Sraghna & Feral & 1 & 32.15 & 7.26 \\
\hline & & Traditional cultivation & 1 & 31.37 & 7.95 \\
\hline & Tamellalt & Traditional cultivation & 1 & 31.46 & 7.98 \\
\hline & Sidi Bou Othmane & High-density cultivation & 1 & 31.70 & 7.69 \\
\hline & Marrakech & High-density cultivation & 2 & 31.69 & 8.11 \\
\hline & & Traditional cultivation & 7 & 31.63 & 8.10 \\
\hline & Tahannaout & Traditional cultivation & 1 & 31.57 & 7.97 \\
\hline & Asni & Feral & 1 & 31.28 & 7.96 \\
\hline \multirow[t]{3}{*}{ Tadla } & Beni Mellal & Wild & 2 & 32.58 & 5.98 \\
\hline & & Traditional cultivation & 1 & 32.21 & 6.83 \\
\hline & El Ksiba & Feral & 2 & 32.32 & 6.39 \\
\hline \multirow[t]{2}{*}{ Zaïane } & Oulmes & Wild & 2 & 33.32 & 6.07 \\
\hline & Oued Zem & Wild & 1 & 33.33 & 6.00 \\
\hline \multirow[t]{5}{*}{ Guerouane } & El Hajeb & High-density cultivation & 2 & 33.70 & 5.63 \\
\hline & & Traditional cultivation & 2 & 33.77 & 5.71 \\
\hline & Meknes & High-density cultivation & 4 & 33.88 & 5.41 \\
\hline & & Traditional cultivation & 3 & 33.85 & 5.39 \\
\hline & Khemisset & Feral & 2 & 33.63 & 5.83 \\
\hline Kandar & Sefrou & Traditional cultivation & 5 & 33.87 & 4.88 \\
\hline \multirow[t]{2}{*}{ Jel } & Taza & Traditional cultivation & 3 & 34.25 & 3.80 \\
\hline & Msoun & Traditional cultivation & 2 & 34.26 & 3.74 \\
\hline \multirow[t]{13}{*}{ Rif } & Tanger & Wild & 1 & 35.79 & 5.92 \\
\hline & Fnideq & Wild & 2 & 35.78 & 5.37 \\
\hline & Tetouan & Wild & 1 & 35.54 & 5.62 \\
\hline & & Feral & 1 & 34.79 & 5.77 \\
\hline & Asilah & Wild & 4 & 35.07 & 5.33 \\
\hline & & Traditional cultivation & 1 & 35.05 & 5.35 \\
\hline & Chefchaouen & Wild & 8 & 35.07 & 5.33 \\
\hline & & Feral & 3 & 35.07 & 5.32 \\
\hline & & Traditional cultivation & 2 & 35.38 & 5.37 \\
\hline & Bni Harchen & Wild & 2 & 35.54 & 5.62 \\
\hline & Ouazzane & Wild & 1 & 34.94 & 5.53 \\
\hline & & Feral & 2 & 34.79 & 5.77 \\
\hline & & Traditional cultivation & 5 & 34.79 & 5.77 \\
\hline
\end{tabular}

This was done with a small spade under the foliage of each olive tree from the upper rhizosphere (the 15-20$\mathrm{cm}$ deep layer inhabited by pleiotropic roots), in the close vicinity of active olive roots. This ensured that roots from weeds or other herbaceous plants were unlikely sampled. On cultivated olive (traditional and high-density 
cultivation), tillage and other human activities are frequent, which could lead to the homogenization of the PPN communities in an orchard. Each orchard was therefore considered as a repetition per modality. The sampling was carried out in each orchard along transects under four trees located at a distance of approximately $10 \mathrm{~m}$. Five sub-samples were collected from each tree. These 20 sub-samples were thoroughly mixed to obtain a single representative sample per orchard. Contrary to cultivated orchards, heterogeneous PPN communities were expected in wild and feral olive trees because human interventions are scarce or absent. Each tree was thus taken as a repetition. Five sub-samples were also collected from each tree and then combined to form one $1-\mathrm{dm}^{3}$ reference sample per tree.

\section{Genetic characterization of the olive tree}

In order to confirm the determination of olive-growing modalities, three olive branches corresponding to soil samples were collected to determine the chloroplast haplotype of each tree (according to [22]). All cultivated olive sampled trees only show the haplotype E1-1. Feral olive sampled trees show only E1-1 or mixtures with E2 and E3 haplotypes (i.e., E2-1, E2-2, E2-4 and E3-3, E3-4). E2 and E3 have been previously detected in Moroccan cultivars, but with frequencies below 5\% [16]. Wild sampled trees show haplotypes characteristic of Moroccan-Iberian oleasters (i.e. E2-5, E2-6, E2-14, E3-4, E3-7, E3-8) and of O. europaea maroccana (M1-1, M1-2, M1-7).

\section{Nematode extraction, identification and quantification}

All of the nematode analyses were performed in the nematode quarantine area (French Government Agreement No 80622) of the Research Unit, "Centre de Biologie pour la Gestion des Populations" (Montpellier, France).

A $250-\mathrm{cm}^{3}$ wet aliquot was taken from each soil sample for nematode extraction using the elutriation procedure [23]. PPN belonging to the Aphelenchida, Dorylaimida, Triplonchida and Tylenchida orders were enumerated in $5-\mathrm{cm}^{3}$ counting chambers [24] and identified at the genus level based on dichotomous keys [25] and at the species level with genus-specific keys. The population levels were expressed per $\mathrm{dm}^{3}$ of fresh soil. Concerning specific identification, the nematode suspensions were preserved in mixture of formalin and glycerine [26], and then adult specimens were processed according to Seinhorst method [27] and mounted onto slides [28] for microscopic observation. Root-knot nematodes (Meloidogyne spp.) were identified at the species level by biochemical (esterase patterns) and molecular (SCAR markers and 28S rDNA D2-D3 expansion segments) approaches [29].

\section{Analyses of nematode diversity}

Several ecological indices were used:

a. Taxonomical diversity: (i) the total number of PPN in a community $(N)$; (ii) the species richness $(S)$; (iii) the Shannon-Wiener diversity index $H^{\prime}\left(H^{\prime}=-\sum \mathrm{p}_{i} l\right.$ $n \mathrm{p}_{i}$, where $\mathrm{p}_{i}$ is the proportion of individuals in each species (iii) that quantifies the local diversity or the heterogeneity of diversity $\left(H^{\prime}\right.$ ranges from 0 to $\left.\ln (S)\right)$; and (iv) the evenness $\left(E=H^{\prime} / \ln S\right)$ that quantifies the regularity of species distribution within the community ( $E$ varies between 0 and 1$)$.

b. Functional diversity: PPN species detected in communities were distributed into life-strategy groups according to the colonizer/persister value ( $c p$-value) of the family to which they belong [30]. The diversity of the community was described by calculating: (i) the plant-parasitic index $\left(\mathrm{PPI}=\sum c p_{i} \mathrm{n}_{i} / \mathrm{N}\right)$, which quantifies the plant-feeding diversity of the communities; (ii) the relative mean abundance (\%) of each $c p$-value class in a community calculated as follows: $R c p_{i}=c p_{i} \mathrm{n}_{i} / \mathrm{N}$; (iii) the genus richness included in each $c p$-value class. PPN species were also assigned to the trophic groups according to their feeding habits [31, 32]: obligate plant feeders (OPF), facultative plant feeders (FPF) that alternatively feed on fungi, and fungal feeders (FF) that alternatively feed on plants. These trophic groups were also described according to (i) the relative mean abundance (\%) of individuals within each of them, and (ii) the genus richness included in each [33].

c. The structure of PPN communities was designed at the genus level. The dominance of each nematode genus in the samples was first estimated by modeling the abundance (A) and the frequency $(\mathrm{F})$ of each genus in the whole samples [34]. Afterwards, PPN community structures were described according to multivariate statistical analyses.

\section{Data analyses}

These diversity indices were calculated using the Vegan library [35]. In order to evaluate the impact of anthropogenic changes on biodiversity and community structures, different olive variables were defined according to olivegrowing modalities: wild (WO), feral (FO), traditional or low-density cultivation (TR) and modern or high-density cultivation (HD), and according to olive irrigation conditions: irrigated or rainfed. The mean values of the different nematode diversity indices were compared according to olive propagation (wild vs cultivated) and to intensification practices (traditional vs high-density, irrigated vs 
rainfed). Principal Component Analysis (PCA) was carried out on nematode genera data in order to describe PPN community structures. To assess the impact of olive anthropogenic changes on taxonomical structures, a coInertia Analysis (CIA) was applied between olive-growing modality data (WO-FO-TR-HD) and PPN genera. The scarcest genera (with total abundance less than 1\%) were then excluded from the dataset prior to running the analysis. These different multivariate analyses and graphs were performed using ade4 library [36, 37]. All analyses were done using $\mathrm{R}$ version 3.3.2 [38]. The Wilcox (nonparametric) test was used for all pair-wise multiple comparisons. Differences obtained at levels of $P<0.05$ were considered to be significant.

\section{Results}

\section{PPN diversity associated with olive trees in Morocco}

The PPN communities associated with olive trees in Morocco were highly diversified. A total of 117 species and 47 genera were identified. They belong to two families of Aphelenchida, to a family of Dorylaimida, to a family of Triplonchida and to 14 families of Tylenchida (Table 2).

At the family level, the Tylenchidae and Telotylenchidae were dispersed in all the regions sampled; they were the most diversified families, including 11, 9 genera in each, respectively. However, each genus was often represented by one or two species only (e.g. Amplimerlinus, Bitylenchus, Tylenchus). Most of these species were very rare as they were detected in one or two sites only (e.g. Aglenchus agricola, Coslenchus gracilis and Paratrophurus loofi in the Rif region). In contrast, the Hoplolaimidae family was represented by two genera only (Helicotylenchus and Rotylenchus), but the number of species identified in each genus was high (11 and 4 species, respectively), and they were distributed in all the regions, except in eastern Morocco (the Kandar and Jel regions). Longidoridae and Trichodoridae nematodes were detected mostly in the Rif region. Root-lesion nematodes (e.g. Pratylenchus) and Pin nematodes Paratylenchidae (e.g. Paratylenchus) were dispersed at all the sites surveyed. Four root-knot nematodes species were identified: Meloidogyne arenaria and M. hapla were detected in the Rif region, $M$. javanica was generally detected in southern Morocco (in the Souss and Haouz regions) and in the Guerouane and Tadla regions. M. spartelensis is a new species identified in the Rif region; another new species seems to occur in the Souss region (identification is in progress). Other families such as Criconematidae and Psilenchidae were detected in a few sites.

Among the 47 identified genera, Filenchus, Helicotylenchus, Merlinius, Paratylenchus, Pratylenchus, Rotylenchus, Tylenchorhynchus and Xiphinema were the most widespread in olive soils. Considering the species level, 11 Helicotylenchus species (Hoplolaimidae) were frequently collected in olive samples. Among them, $H$. crassatus was clearly the most dominant species (occurring in $58 \%$ of the samples). It was present in all regions except in the Jel and Kandar regions. $H$. dihystera and $H$. varicaudatus also occurred in 43 and $32 \%$ of the samples, respectively. In contrast, $H$. exallus and $H$. minzi, detected in the Guerouane region, and H. pseudorobustus, detected in the Haouz region, were scarcer. In addition, Merlinius brevidens (Telotylenchidae) and Filenchus filiformis (Tylenchidae) were also frequently recovered (51 and $40 \%$ of the samples, respectively).

\section{Diversity of PPN communities according to anthropogenic changes}

Diversity indices mean values were compared between to the four olive-growing modalities and between rainfed and irrigated olive samples.

\section{(a) Taxonomical diversity}

The total number of PPN $(N)$ was up to two times higher on cultivated (HD \& TR) than on non-cultivated olive (WO \& FO). Similarly on irrigated olive, the total number of PPN was higher (Table 3). In contrast, the PPN communities were significantly richer in species $(S)$, more diversified $\left(H^{\prime}\right)$ and more homogenously distributed $(E)$ in communities on WO and FO and on rainfed olive than on TR and HD and on irrigated olive.

\section{(b) Functional diversity}

The PPN identified were allocated in all the parasitic $c p$ values ( $c p-2$ to $c p-5$ groups, Table 2$)$. The WO and HD modalities revealed nematode communities with significantly higher plant-parasitic indices (PPI) than those in FO and in TR orchards (Table 4). This means that WO and HD olive areas had significantly more plant-feeding nematodes with higher $c p$ values than other olive systems. The most opportunist/colonizer PPN ( $c p-2$ and $c p-3$ ) dominated in all the communities (44 and $48 \%$, respectively; Table 2 ). The overall abundance and occurrence of the persister nematodes $(c p-4$ and $c p-5)$ was very low ( $4 \%$ for each $c p$ class). Any effect was recorded on the $c p-4$ class. $C p-2$ and $c p-3$ nematodes were more abundant in TR and HD, while $c p-5$ nematodes occurred more often in WO areas and were completely absent in HD orchards.

Concerning the trophic groups within communities, the OPF nematodes were the most dominant $(62 \%)$, while the FPF and the FF nematodes were the least frequent (26 and $12 \%$, respectively). FF nematodes were significantly more numerous in WO areas (Table 4). FPF and OPF nematodes were more abundant in TR and 


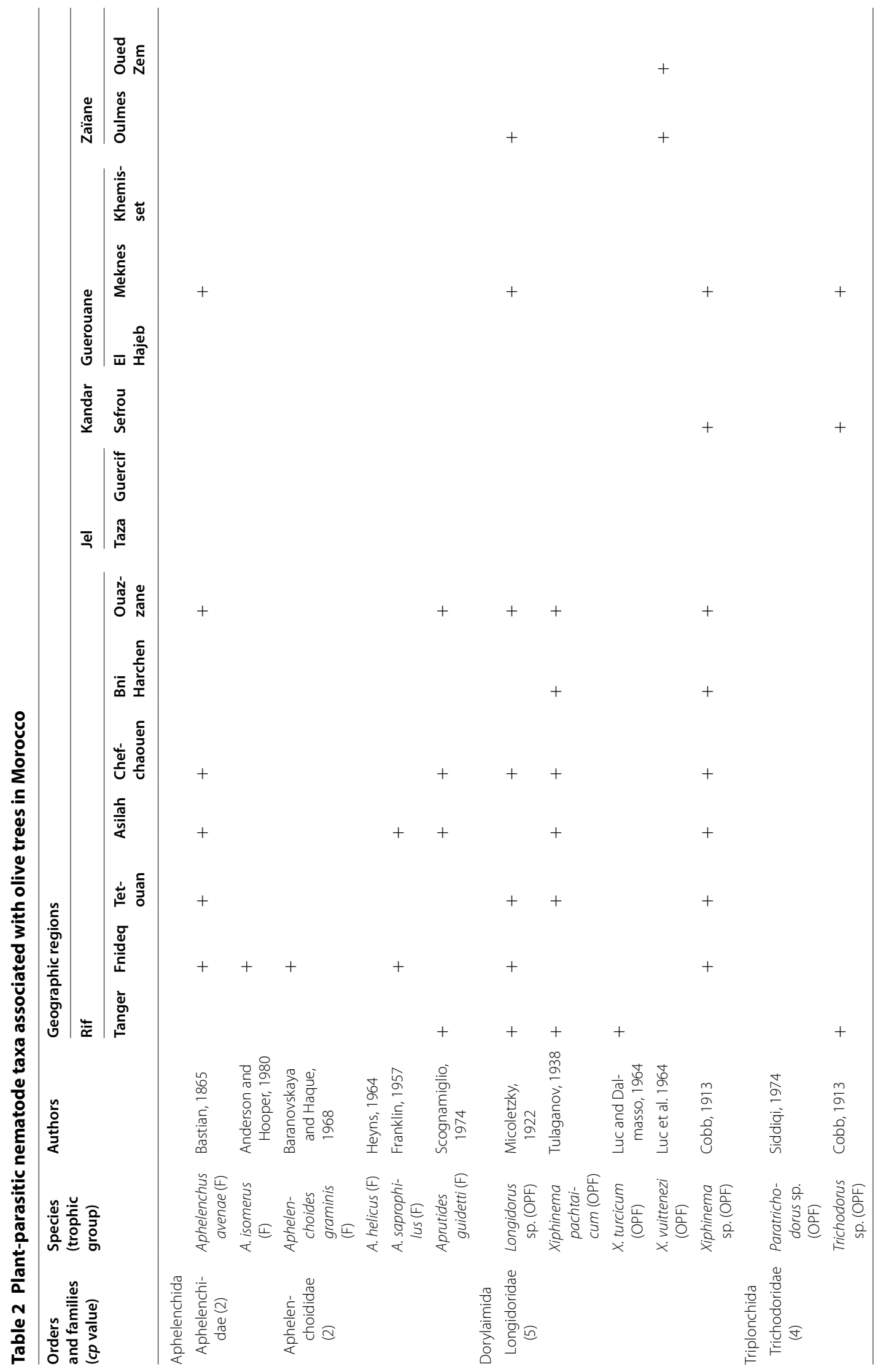




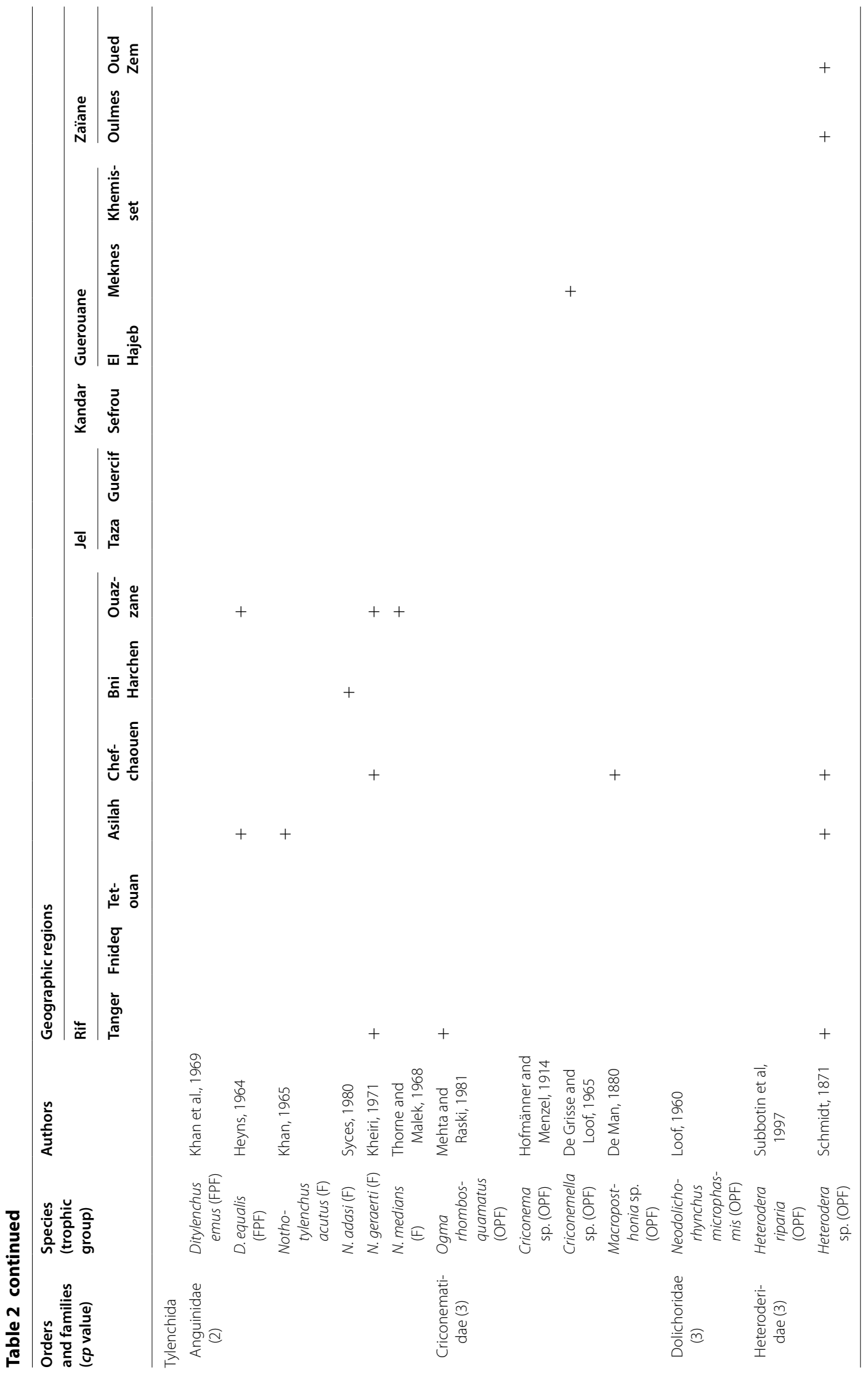




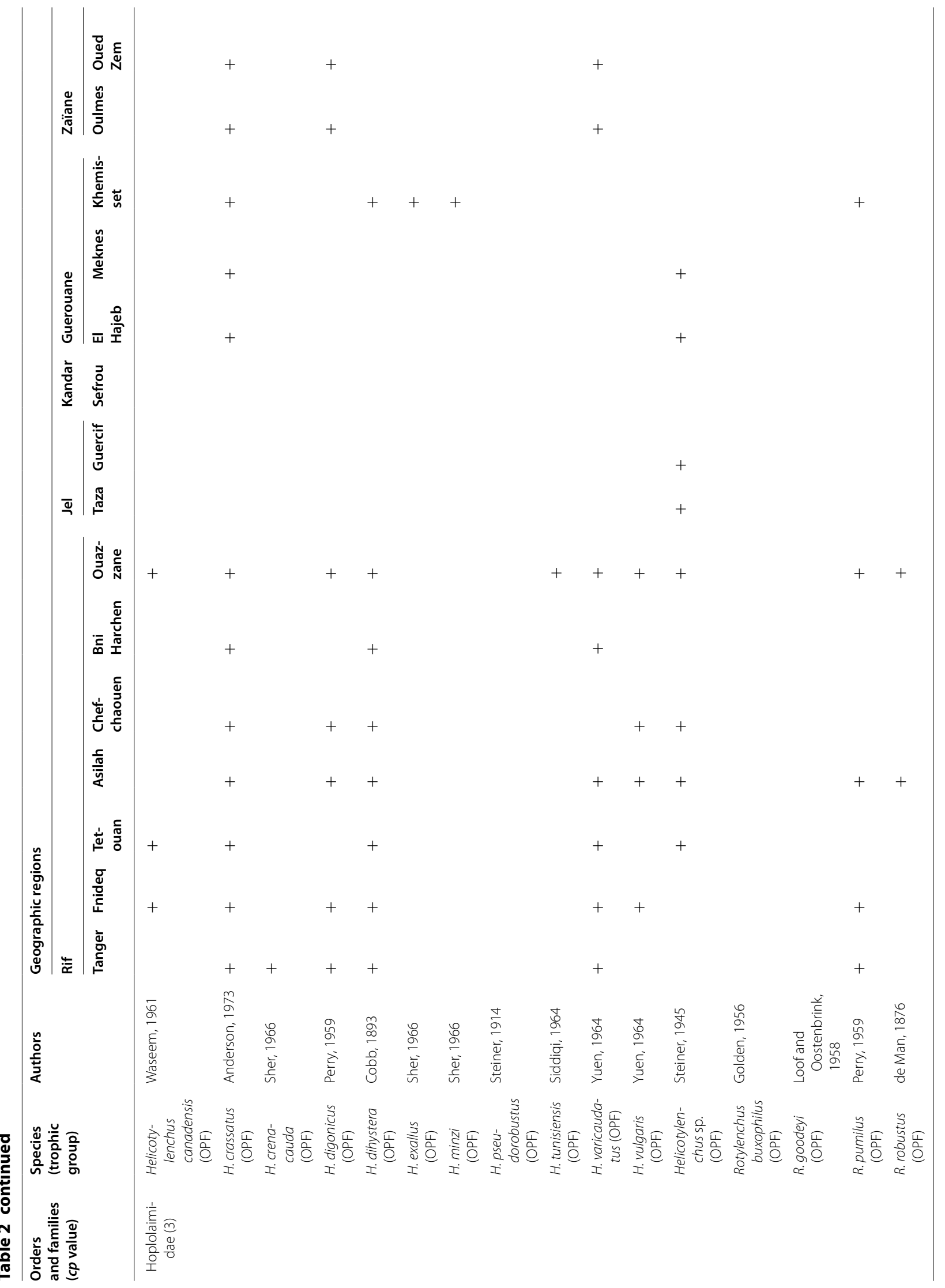




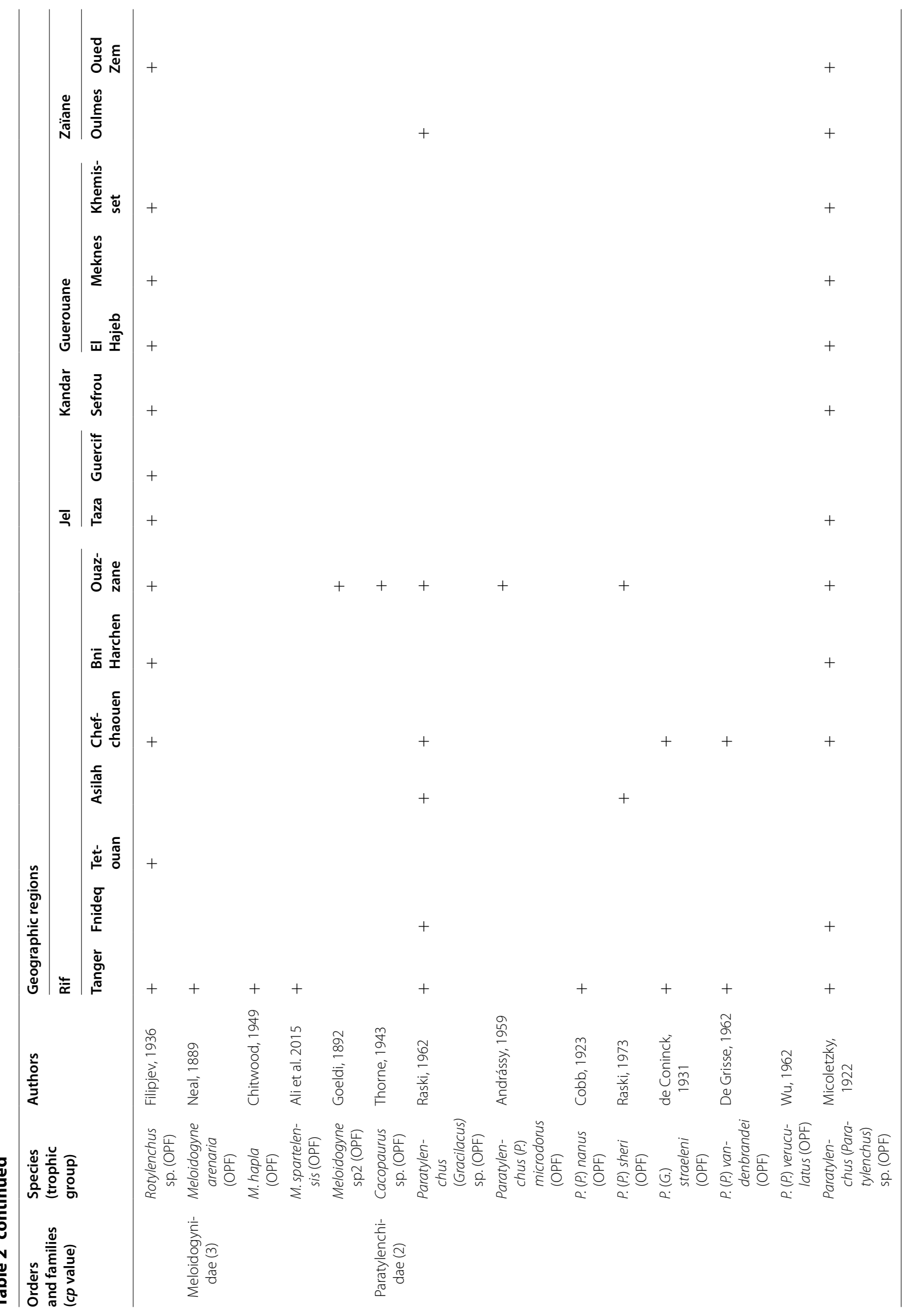




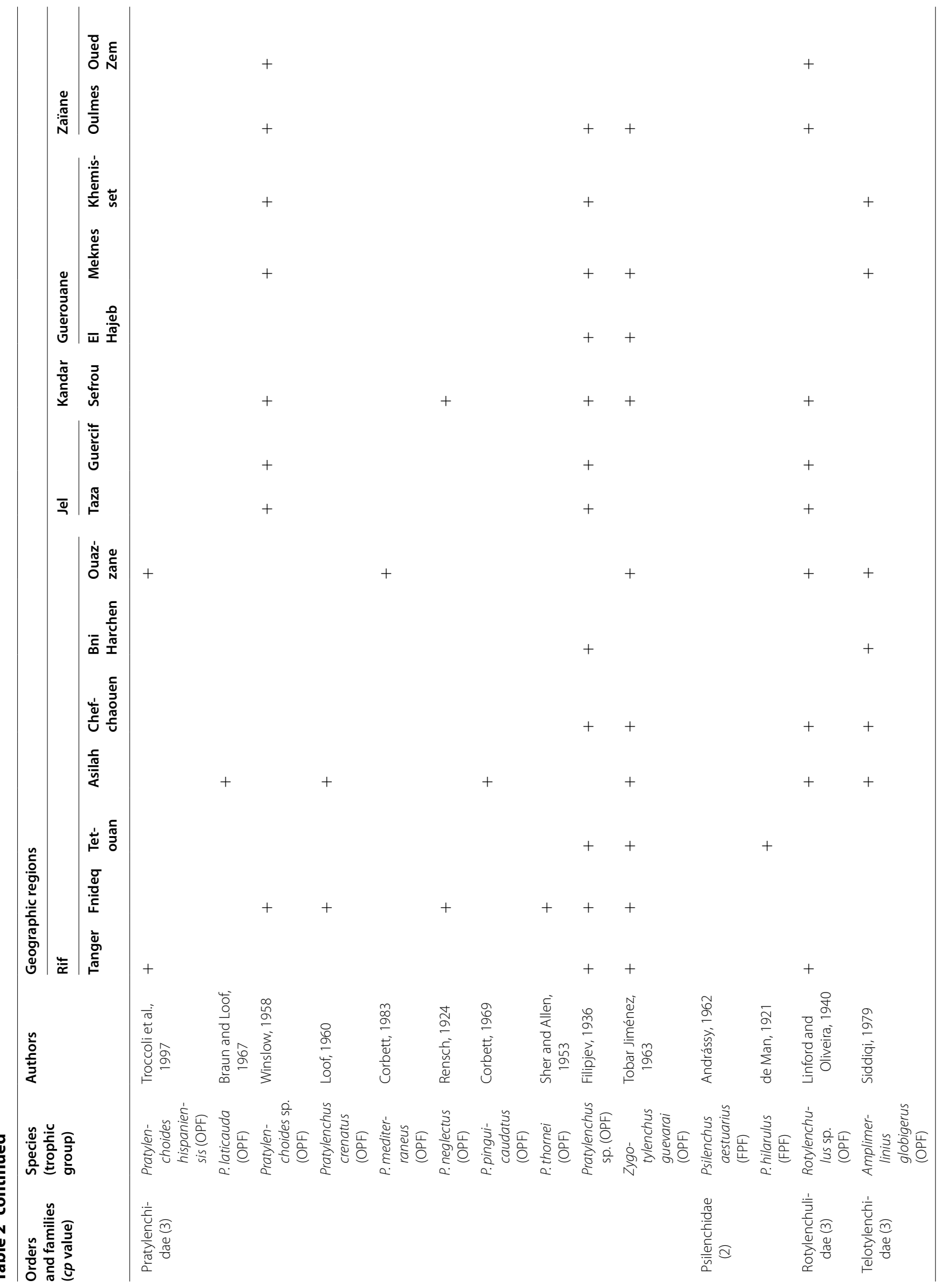




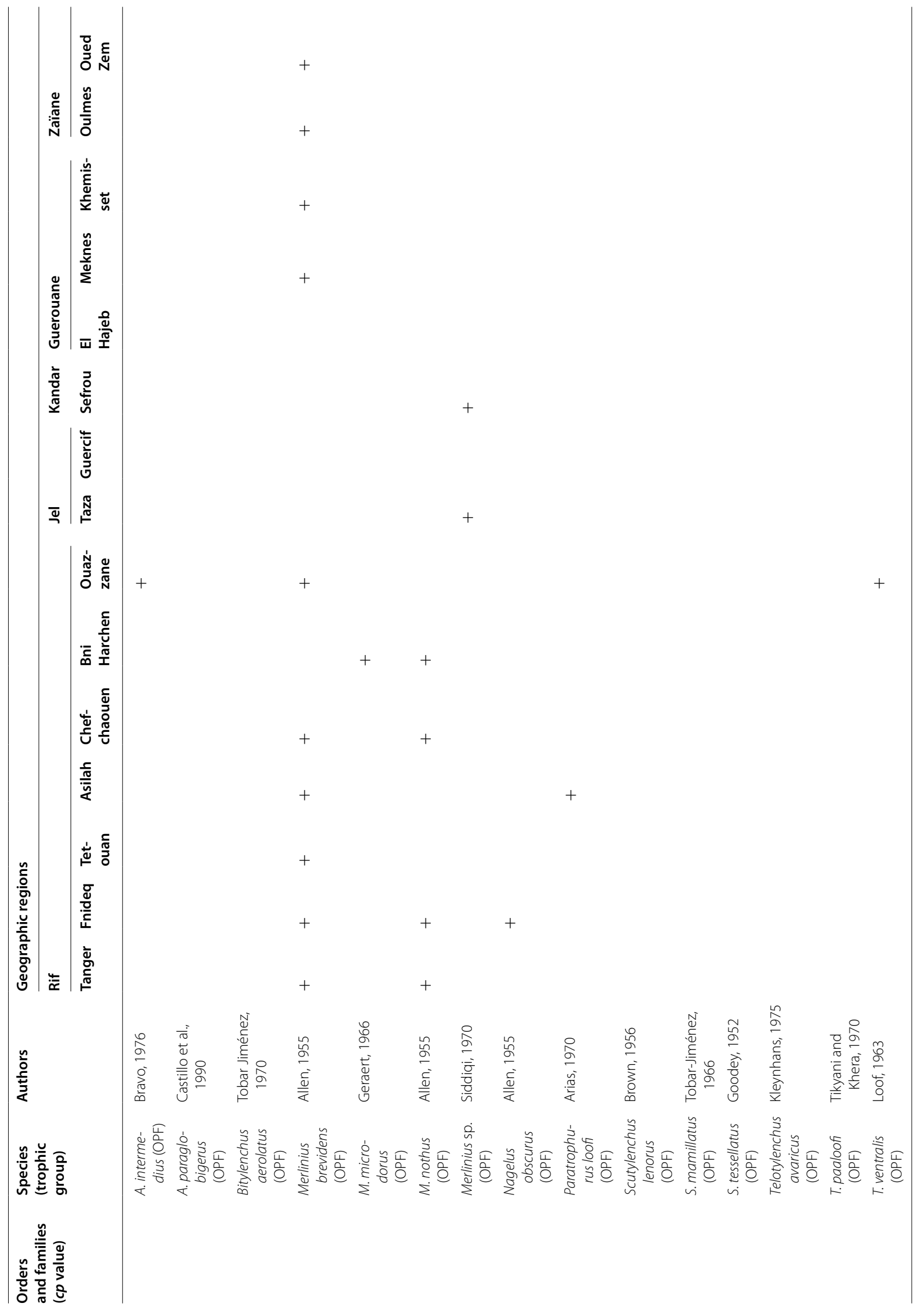




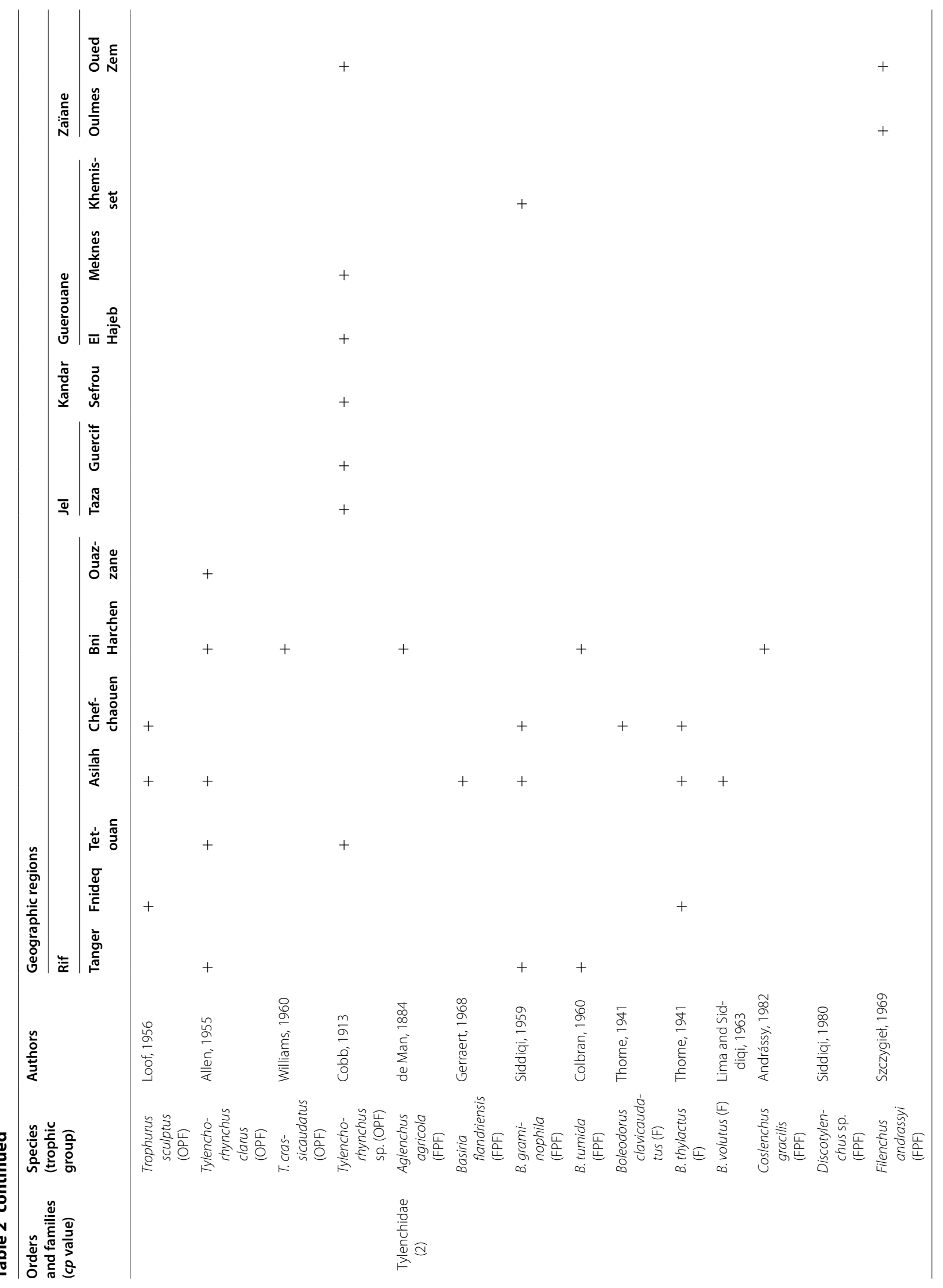




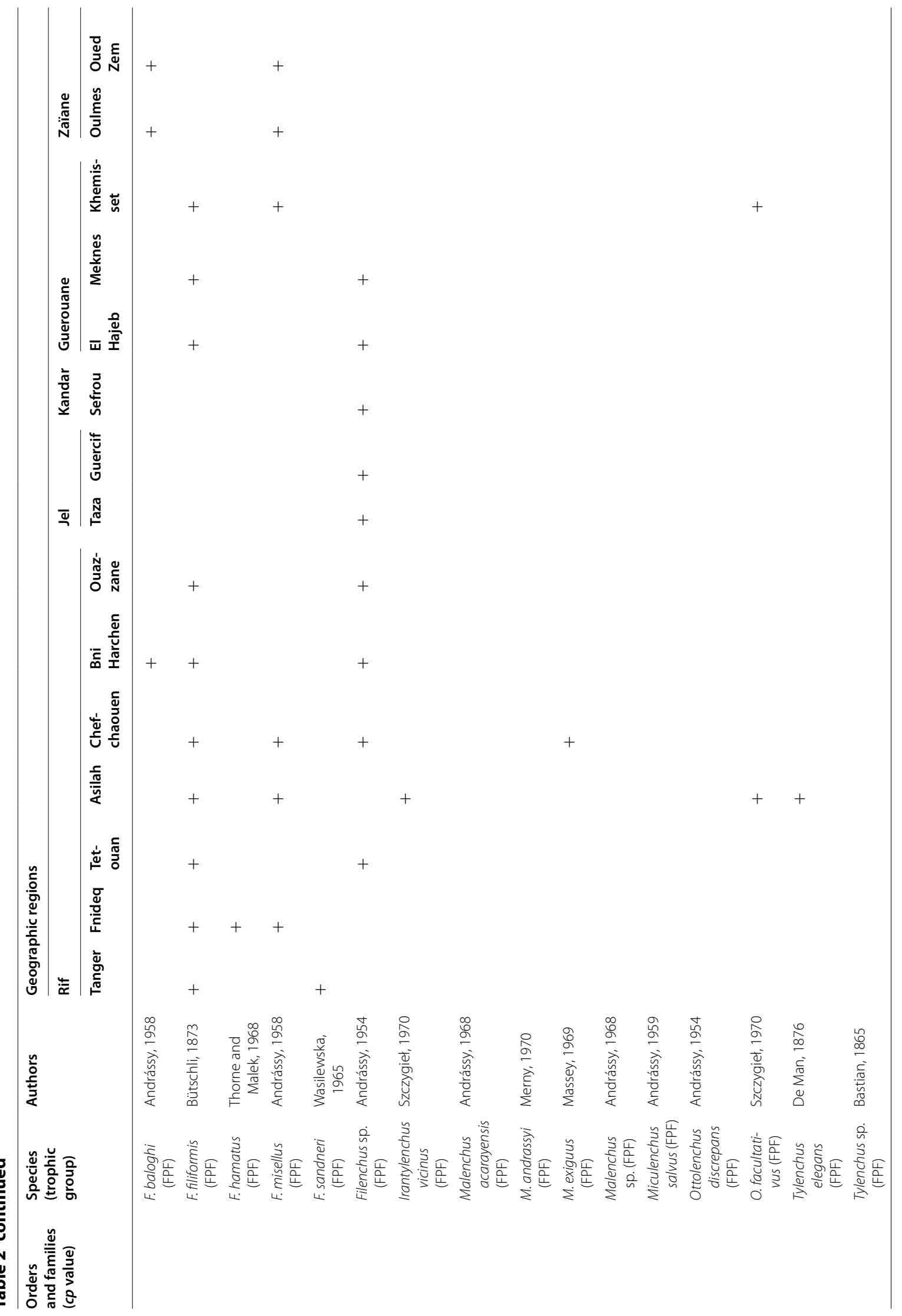




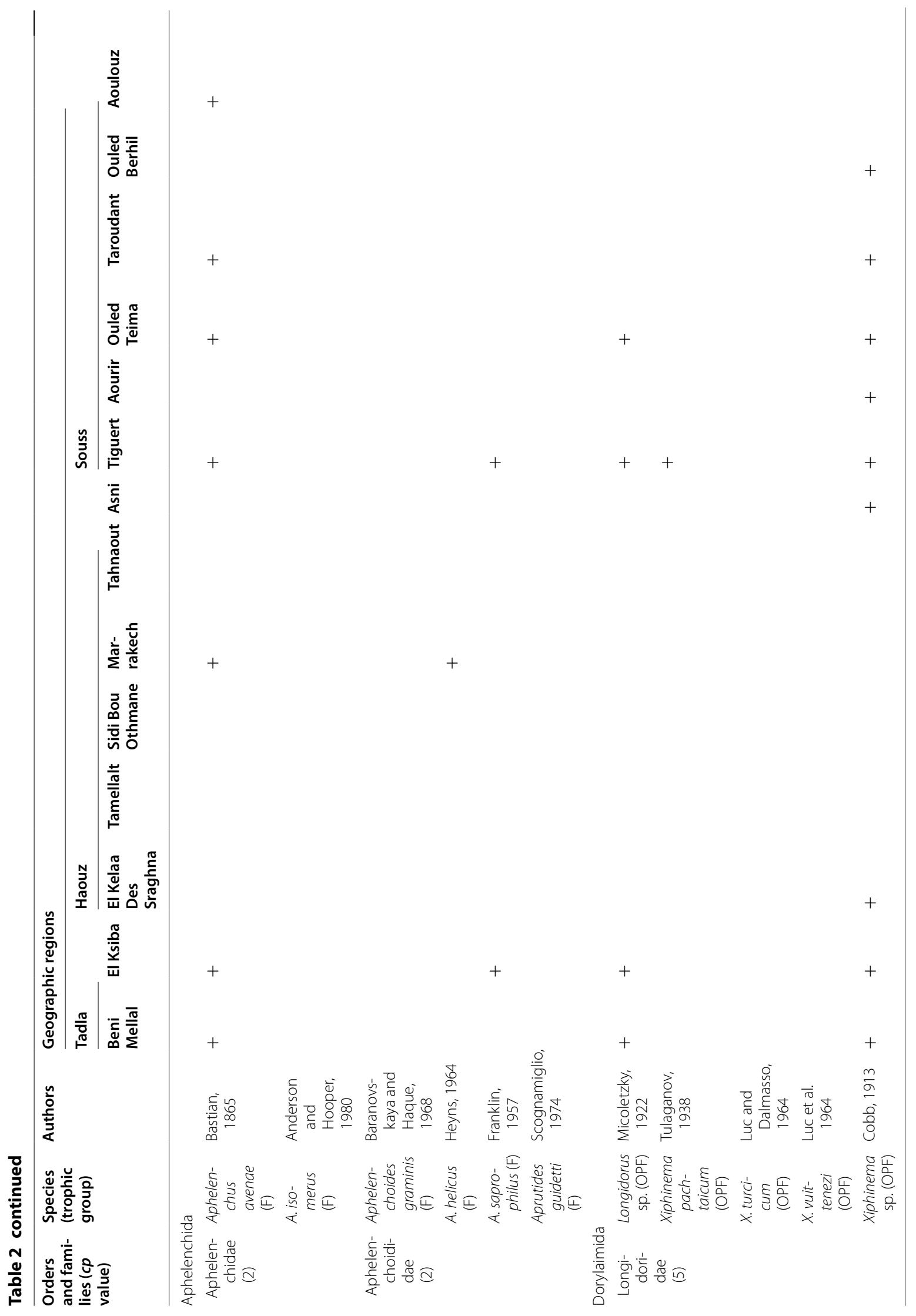




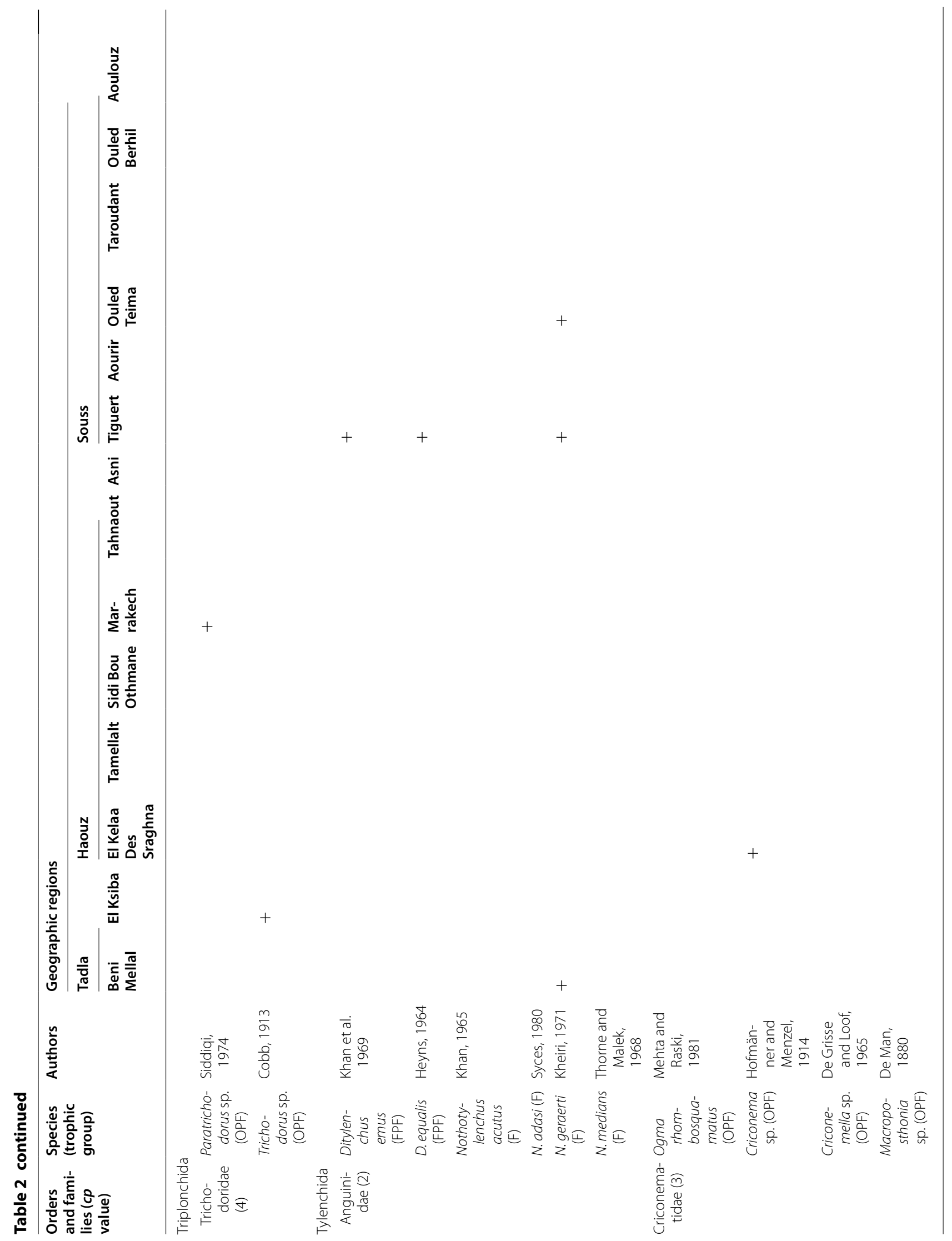




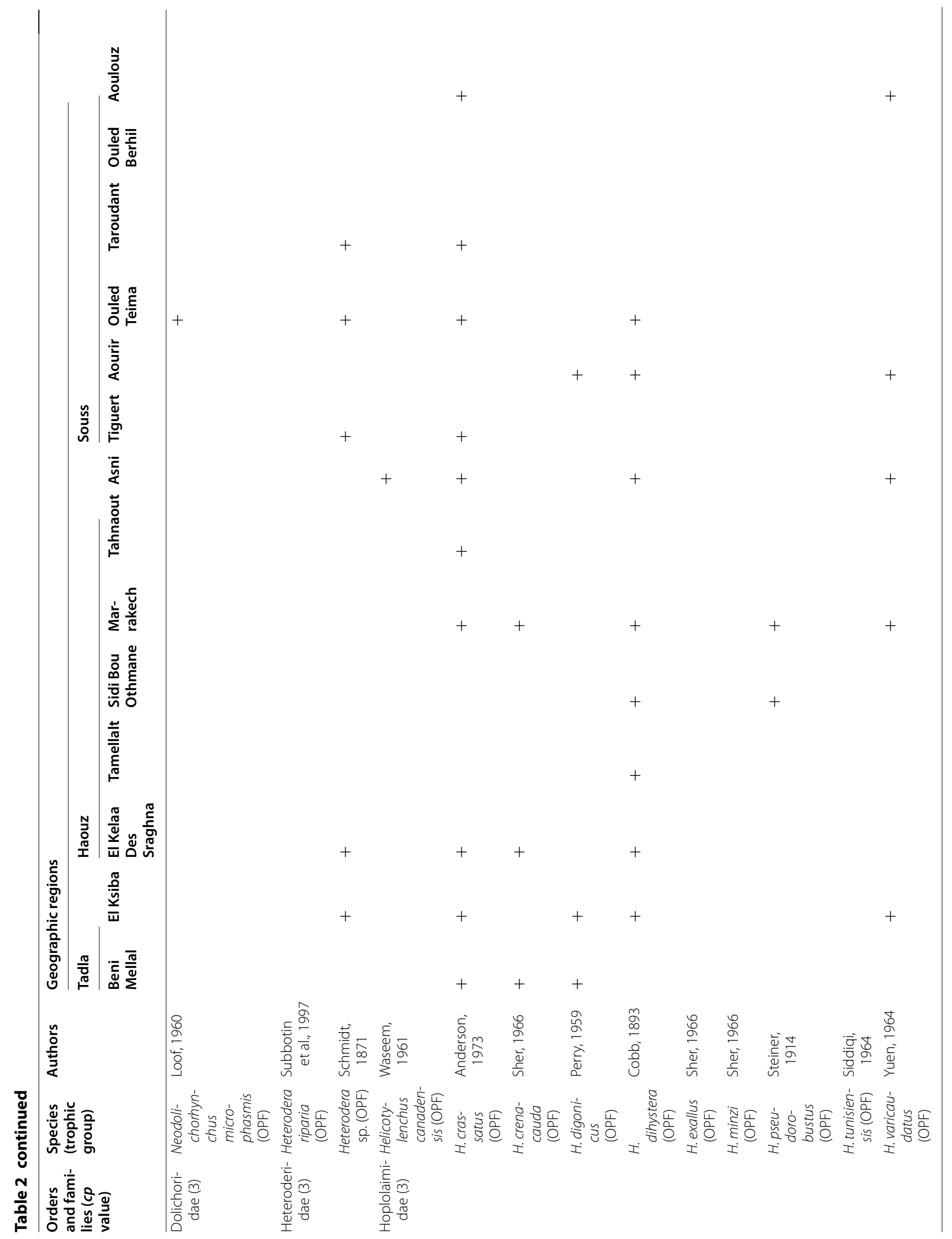




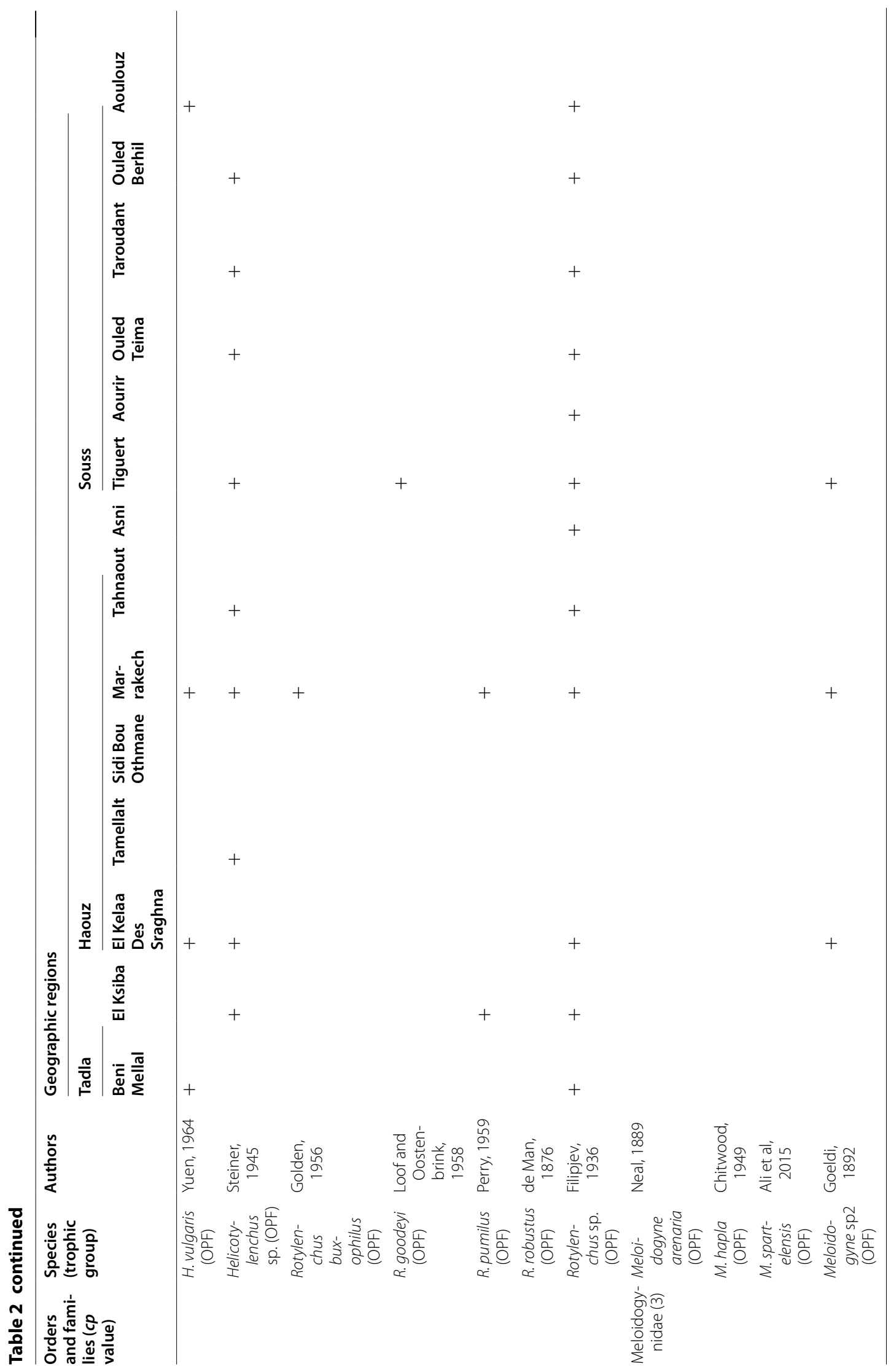




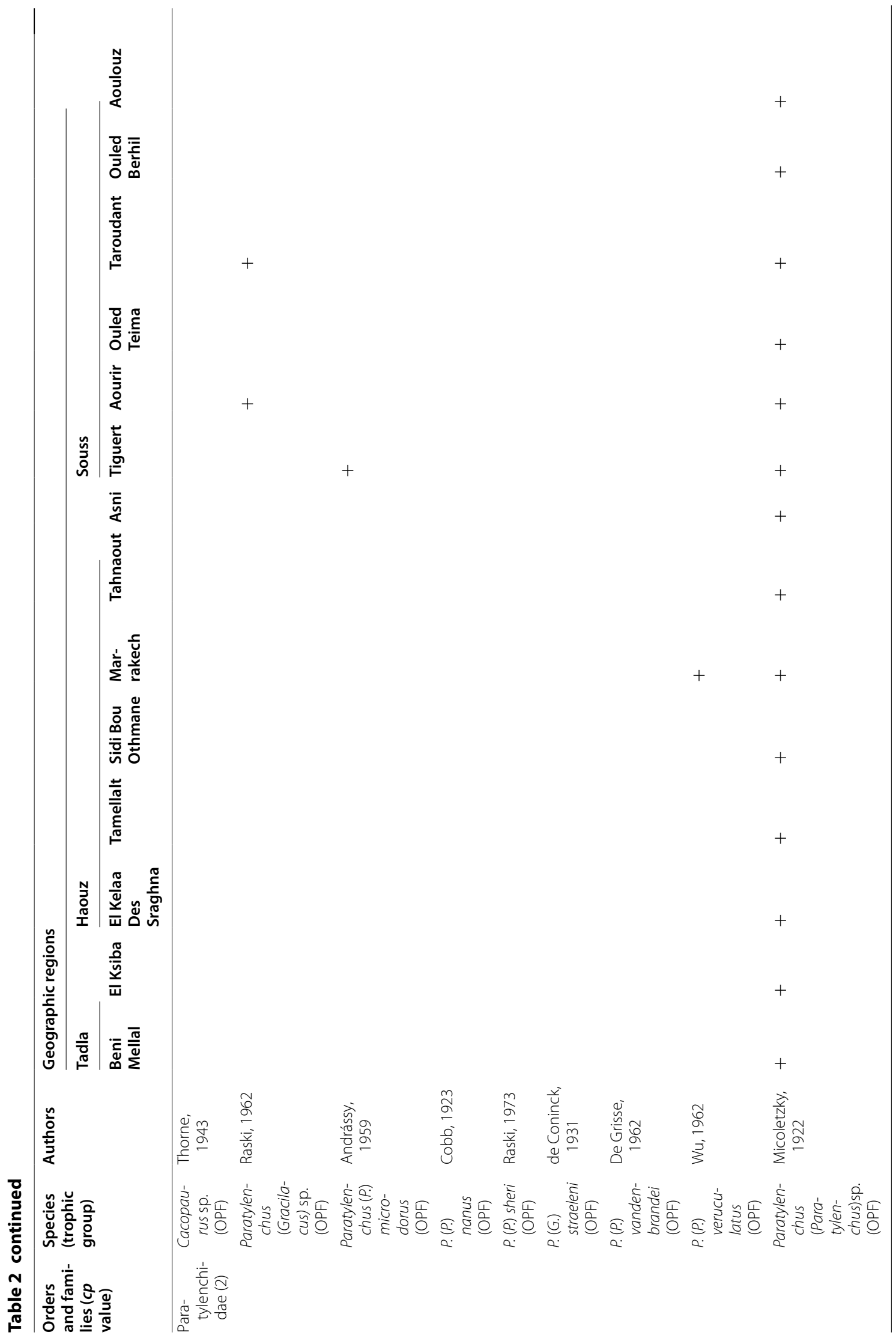




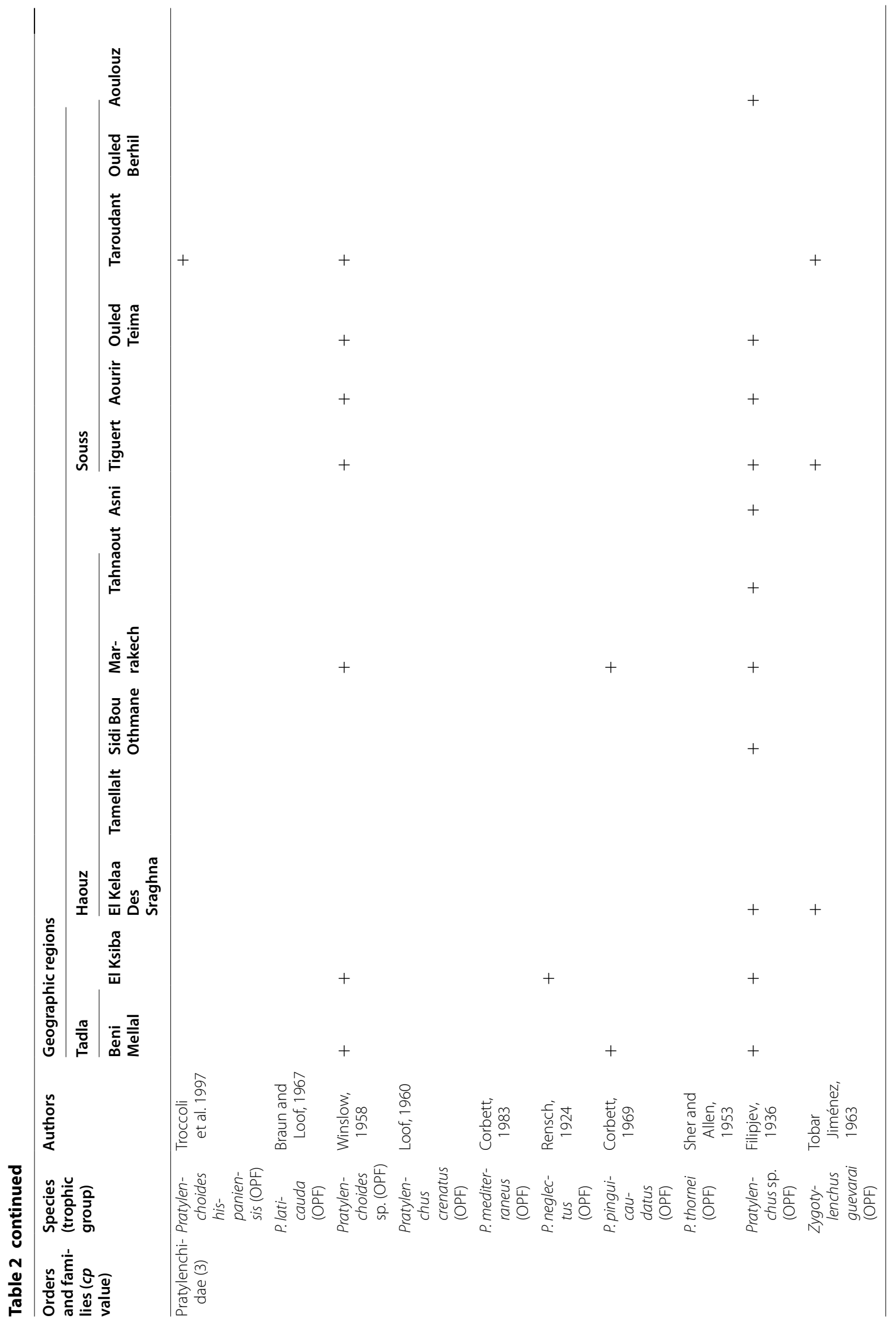




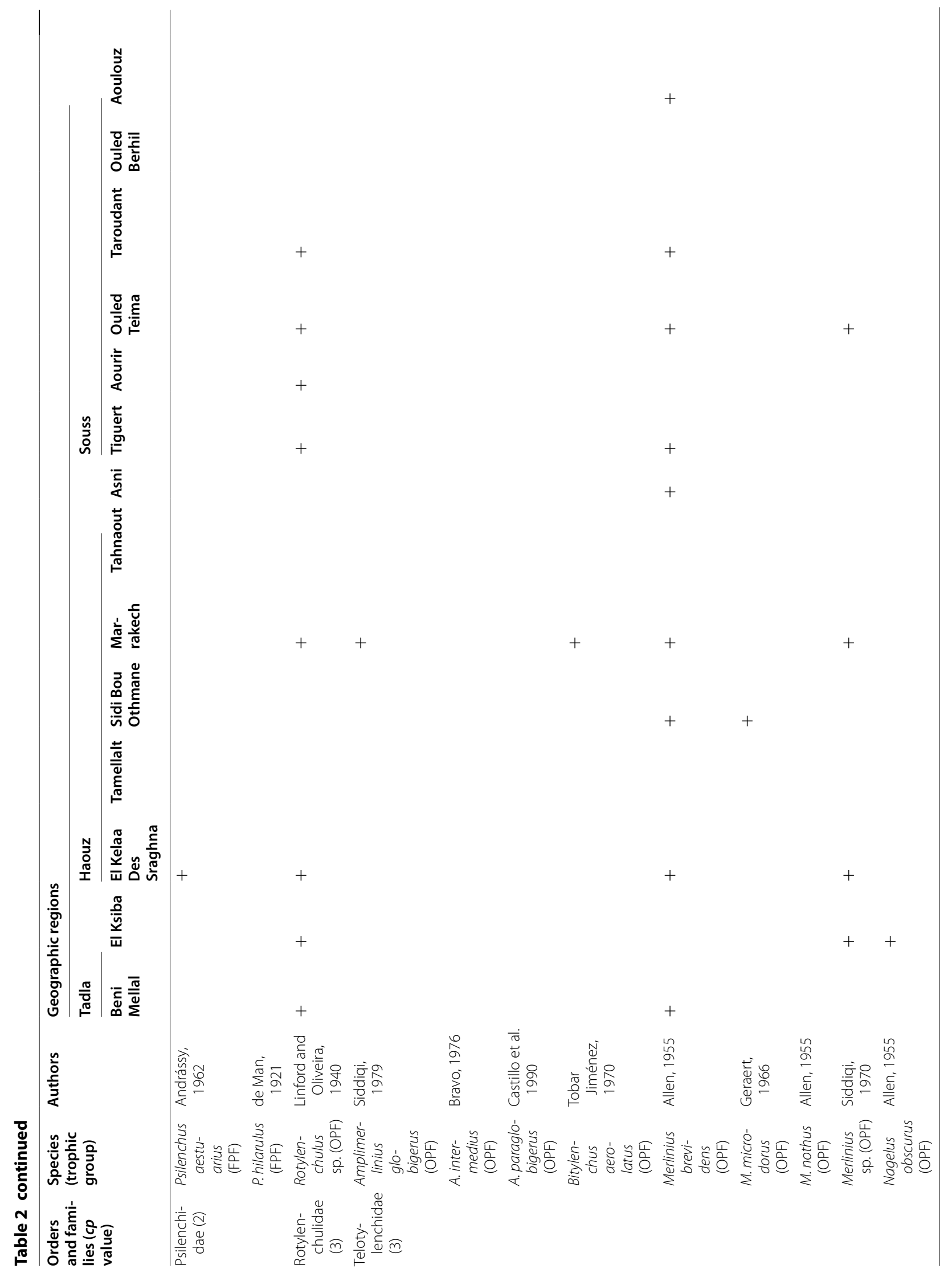




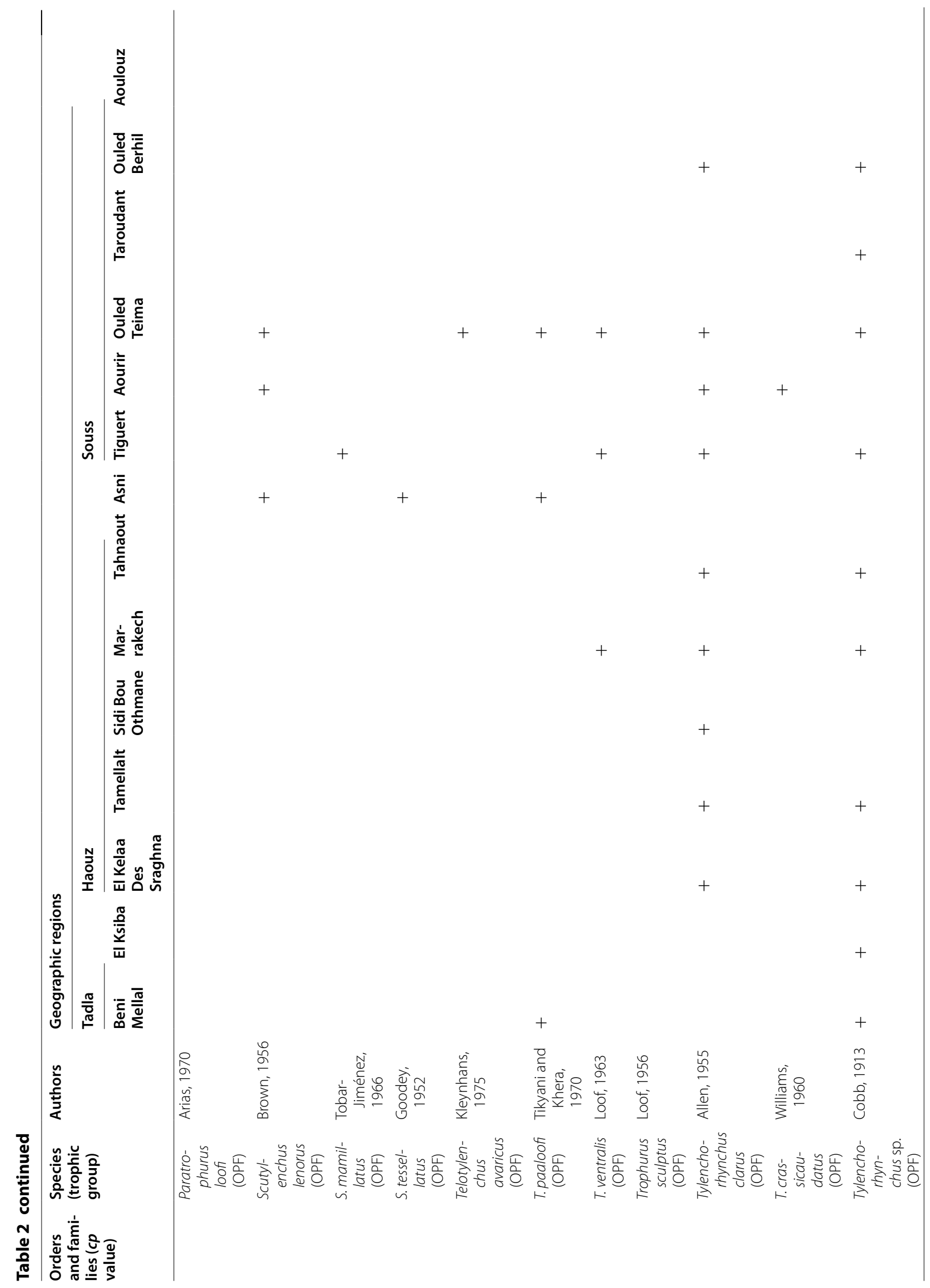




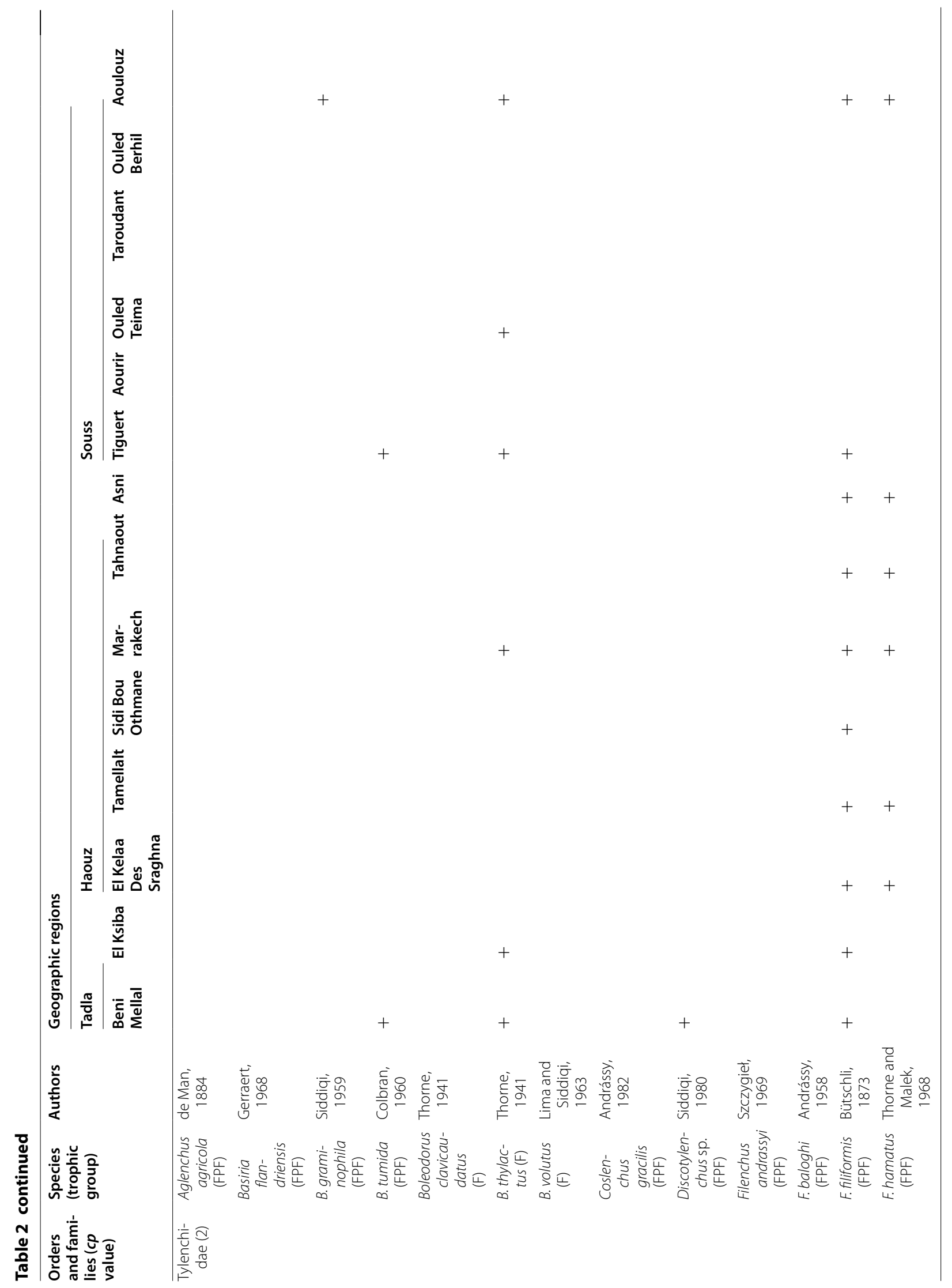




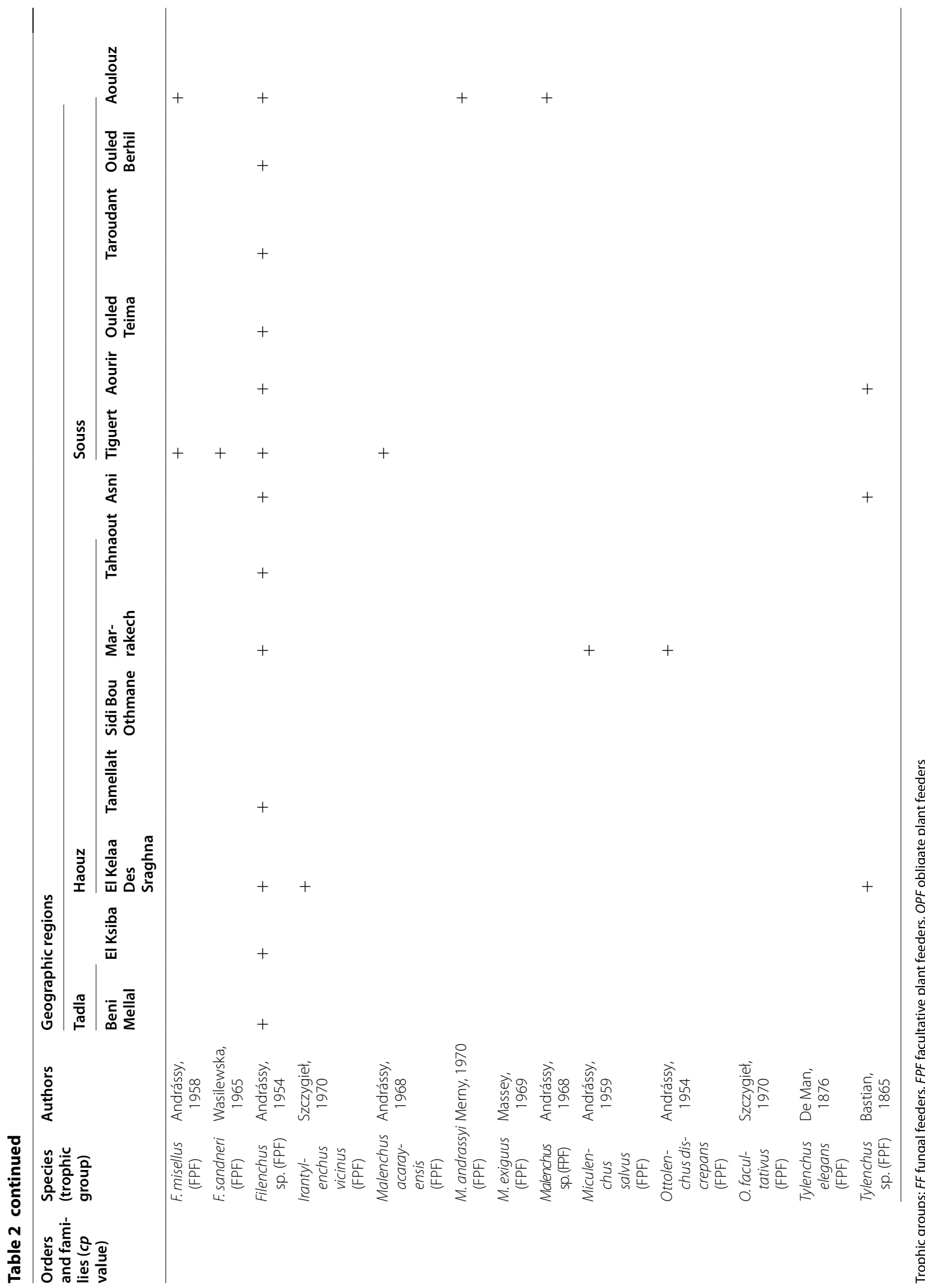


Table 3 Taxonomical diversity indices in PPN communities associated with olive (mean values) according to olivegrowing modalities and water supply

\begin{tabular}{llllll}
\hline Olive variables & Nb of samples & $\mathbf{N}$ & $\mathbf{S}$ & $\mathbf{H}^{\prime}$ & $\mathbf{E}$ \\
\hline Growing modality & & & & & \\
WO & 88 & $2227 b$ & $10.31 a$ & $1.55 a$ & $0.68 a$ \\
FO & 75 & $2751 b$ & $9.51 a$ & $1.58 a$ & $0.69 a$ \\
TR & 40 & $4369 a$ & $7.50 b$ & $1.24 b$ & $0.58 a$ \\
HD & 10 & $4352 a$ & $6.90 b$ & $1.04 b$ & $0.50 b$ \\
Water supply & & & & & \\
Rainfed & 171 & $2512 b$ & $9.87 a$ & $1.56 a$ & $0.69 a$ \\
Irrigated & 42 & $4365 a$ & $7.36 b$ & $1.19 b$ & $0.56 b$ \\
\hline
\end{tabular}

The letters $(a-c)$ indicate significant differences among the variables measured according to ANOVA and Wilcoxon tests. $P<0.05$

WO wild olive, $F O$ feral olive, $T R$ traditional cultivation, $H D$ high-density cultivation, $N$ total number of PPN $/ \mathrm{dm}^{3}$ of soil, $S$ species richness, $H^{\prime}$ local diversity, E evenness

HD orchards,w respectively. The ratio between FPF and OPF nematodes was unbalanced in favor of OPF in HD orchards, and in favor of FPF in TR orchards and in FO areas. The rainfed-irrigation modalities did not have any effect on the trophic groups.

The $c p-2, c p-3$, FPF and OPF functional groups were represented by the highest number of genera $(44,48,26$ and $62 \%$, respectively). Comparing this richness in each group between olive-growing modalities only, the PPN communities detected in $\mathrm{WO}$ and FO demonstrated higher richness and diversity compared to those detected in TR and HD (Table 5).

\section{(c) Community patterns}

Community structure was described at the genus level. Modeling the dominance of each genus in the samples (Fig. 2a), 83\% of the genera were classified as less frequent
( $\mathrm{F}<30 \%)$ according to the model and $35 \%$ as occasional $(\mathrm{F}<5 \%)$. A total of $62.5 \%$ of the nematode genera were classified as highly abundant according to the abundance threshold defined by the model ( $\mathrm{A}=200$ nematodes/ $\mathrm{dm}^{3}$ of soil). Eight genera were classified as dominant ( $\mathrm{F} \geq 30 \%$ and $\mathrm{A} \geq 10,000$ nematodes $/ \mathrm{dm}^{3}$ of soil): Filenchus and Helicotylenchus (F > 80\%); and Rotylenchus, Merlinius, Paratylenchus, Xiphinema, Pratylenchus and Tylenchorhynchus $(40<\mathrm{F}<70 \%)$. Six other highly abundant genera were less frequent, including root-knot nematodes (Meloidogyne spp., $\mathrm{F}=12.2 \%$ ) and cyst nematodes (Heterodera spp., $\mathrm{F}=10 \%$ ). No genus was found to be frequent and in low abundance.

As shown by the PCA loading plot of the nematode taxa (Fig. 2b), Hoplolaimidae nematodes (Helicotylenchus and Rotylenchus), and Paratylenchus, Filenchus and Pratylenchus genera to a lesser extent, were correlated to the PC1 axis (negative values). The PC2 axis indicated contrasted positions for Tylenchorhynchus spp. (negative values), opposed to Boleodorus, Xiphinema, Nothotylenchus, Merlinius, Rotylenchulus, Meloidogyne, Heterodera and Telotylenchus (positive values).

\section{Correspondences between PPN community patterns and olive-growing modalities}

Considering olive-growing modalities, the loading plot of the Co-Inertia Analysis (CIA) analysis between nematode and olive data (Fig. 3) indicated an important contribution of the anthropogenic gradient (WO-FO-TR-HD) to the CIA1 axis. The CIA2 axis was essentially correlated with the feral growing modality (FO, positive values) and with the wild olive (WO, negative values). Regarding the projection of the nematode genera in the loading plot (Fig. 3), the analysis indicated that the genera Merlinius, Xiphinema, Heterodera, Nothotylenchus, Rotylenchulus and Boleodorus were correlated with WO. In contrast,

Table 4 Functional diversity in PPN communities on olive (mean values) according to olive-growing modalities and water supply

\begin{tabular}{|c|c|c|c|c|c|c|c|c|}
\hline Olive variables & PPI & $\mathrm{R} c p-2$ & $\mathrm{Rcp}-3$ & $\mathrm{Rcp}-4$ & Rcp-5 & $\mathrm{FF}$ & FPF & OPF \\
\hline \multicolumn{9}{|l|}{ Growing modality } \\
\hline WO & $2.65 a$ & $45.58 a$ & $48.89 b$ & 0.08 & $5.45 a$ & $8.69 a$ & $32.63 b$ & $58.68 a b$ \\
\hline $\mathrm{FO}$ & $2.57 a b$ & $46.19 a$ & $52.19 b$ & 0.03 & $1.59 b$ & $3.62 b$ & $39.35 a b$ & $57.03 a b$ \\
\hline TR & $2.49 b$ & $52.62 a$ & $46.68 b$ & 0.04 & $0.66 b$ & $3.69 b$ & $46.89 a$ & $49.42 b$ \\
\hline$H D$ & $2.74 a$ & $25.96 b$ & $73.71 a$ & 0.33 & $0.00 b$ & $0.12 b$ & $25.13 b$ & $74.76 a$ \\
\hline \multicolumn{9}{|l|}{ Water supply } \\
\hline Rainfed & 2.61 & 45.91 & 50.69 & 0.05 & $3.35 a$ & 5.93 & 36.28 & 57.78 \\
\hline Irrigated & 2.55 & 46.27 & 53.11 & 0.11 & $0.50 b$ & 2.84 & 41.71 & 55.45 \\
\hline
\end{tabular}

The letters $(\mathrm{a}-\mathrm{c})$ indicate significant differences among the variables measured according to ANOVA and Wilcoxon tests. $P<0.05$ 
Table 5 Genus richness of PPN within each functional group according to olive-growing modalities

\begin{tabular}{|c|c|c|c|c|c|c|c|}
\hline Olive-growing modalities & $c p-2$ & $c p-3$ & $c p-4$ & $c p-5$ & $\mathrm{FF}$ & FPF & OPF \\
\hline Wo & 24 & 23 & 1 & 3 & 5 & 14 & 32 \\
\hline $\mathrm{FO}$ & 13 & 14 & 1 & 2 & 3 & 8 & 19 \\
\hline TR & 11 & 11 & 1 & 2 & 4 & 6 & 15 \\
\hline $\mathrm{HD}$ & 5 & 11 & 2 & 0 & 1 & 3 & 14 \\
\hline
\end{tabular}

WO wild olive, FO feral olive, $T R$ traditional cultivation, $H D$ high-density cultivation, $c p-2$ to $c p$-5 $c p$-values, $F F$ fungal feeders, $F P F$ facultative plant feeders, $O P F$ obligate plant feeders

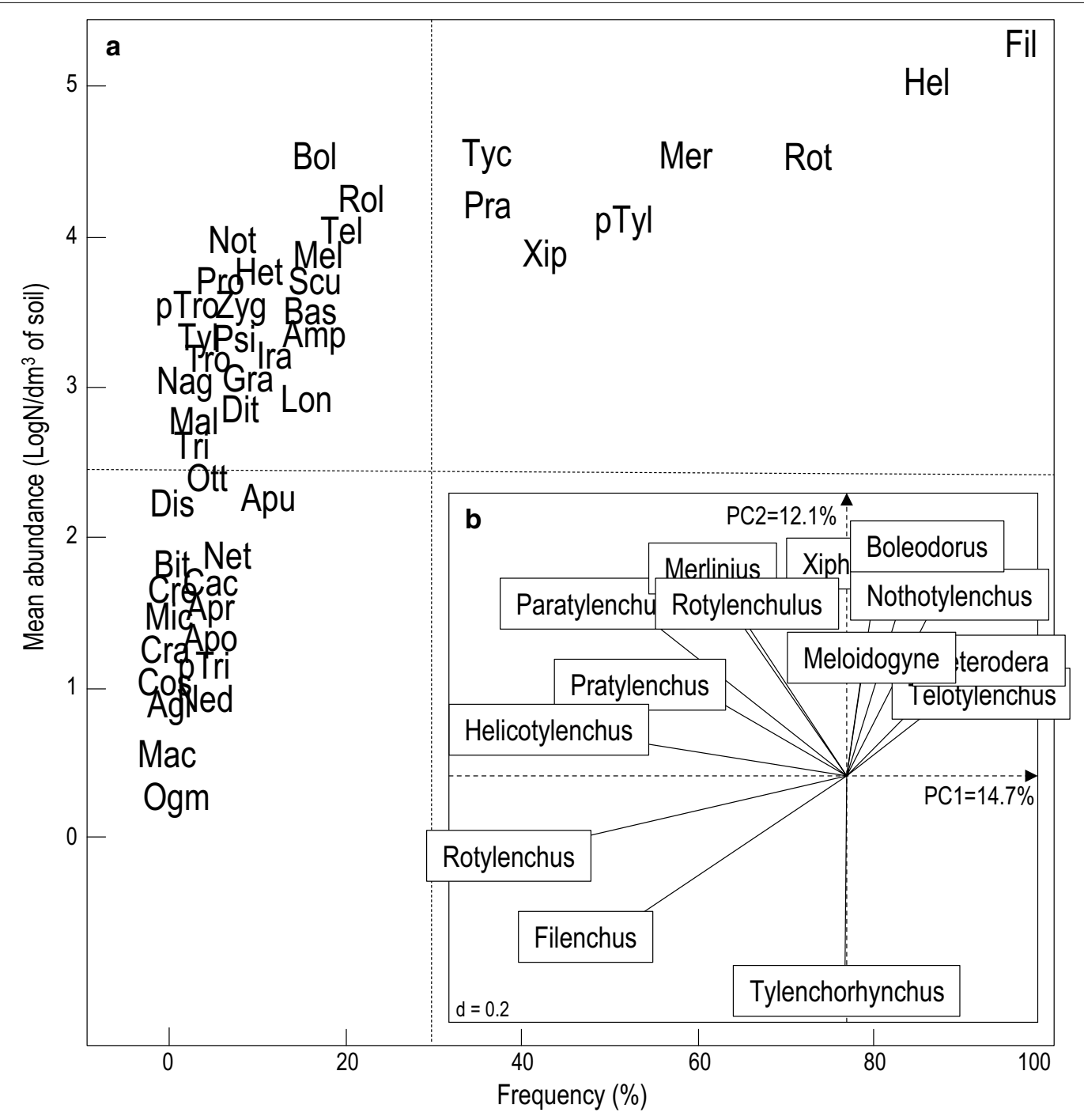

Fig. 2 Plant-parasitic nematode communities in the olive areas surveyed in Morocco. a Dominance diagram of the nematode genera. Codes for nematode genera are given in Table 6. Dotted lines indicate delineation between low and high abundances and frequencies as described in [34]. $\mathbf{b}$ Plant-parasitic nematode community patterns (PCA loading plot for the nematode genera)

Meloidogyne and Tylenchorhynchus were enhanced by cultivation practices (especially HD). The other nematode genera (Filenchus, Pratylenchus) were more closely related to TR, while Telotylenchus, Helicotylenchus,
Rotylenchus and Paratylenchus were more closely related to FO. The mean comparisons of nematode abundances between the modality groups arranged according to their CIA1 eigenvalues (HD, TR and WO + FO) (Fig. 3) 
Table 6 Nematodes genera and their corresponding codes

\begin{tabular}{|c|c|c|c|c|c|}
\hline PPN genus & Code & PPN genus & Code & PPN genus & Code \\
\hline Aglenchus & $\mathrm{Agl}$ & Helicotylenchus & $\mathrm{Hel}$ & Paratrophorus & pTro \\
\hline Amplimerlinius & Amp & Heterodera & Het & Paratylenchus & pTyl \\
\hline Aphelenchoides & Apo & Irantylenchus & Ira & Pratylenchoides & Pro \\
\hline Aphelenchus & Apu & Longidorus & Lon & Pratylenchus & Pra \\
\hline Aprutides & Apr & $\begin{array}{l}\text { Macroposthe- } \\
\text { nia }\end{array}$ & Mac & Psilenchus & Psi \\
\hline Basiria & Bas & Malenchus & Mal & Rotylenchulus & Rol \\
\hline Bitylenchus & Bit & Meloidogyne & Mel & Rotylenchus & Rot \\
\hline Boleodorus & $\mathrm{Bol}$ & Merlinius & Mer & Scutylenchus & Scu \\
\hline Cacopaurus & $\mathrm{Cac}$ & Miculenchus & Mic & Telotylenchus & Tel \\
\hline Coslenchus & Cos & Nagelus & Nag & Trichodorus & Tri \\
\hline Criconema & Cra & $\begin{array}{l}\text { Neodolicho- } \\
\text { rhynchus }\end{array}$ & Ned & Trophurus & Tro \\
\hline Criconemella & Cre & Neotylenchus & Net & $\begin{array}{l}\text { Tylenchorhyn- } \\
\text { chus }\end{array}$ & Tyc \\
\hline Discotylenchus & Dis & Nothotylenchus & Not & Tylenchus & Tyl \\
\hline Ditylenchus & Dit & Ogma & Ogm & Xiphinema & Xip \\
\hline Filenchus & Fil & Ottolenchus & Ott & Zygotylenchus & Zyg \\
\hline Gracilacus & Gra & Paratrichodorus & pTri & & \\
\hline
\end{tabular}

confirmed that Meloidogyne and Tylenchorhynchus nematodes were significantly more abundant in HD orchards compared to TR orchards or to WO + FO. Some significant differences were also detected between traditional and non-cultivated olive orchards. However, other nematodes such as Merlinius, Xiphinema and Heterodera were found to be significantly more abundant in $\mathrm{WO}+\mathrm{FO}$ compared to cultivated olive conditions (HD, TR).

\section{Discussion}

Biodiversity is an essential ecological phenomenon because it represents a complex set of interacting ecological, evolutionary, biogeographical and physical processes [39]. Native biodiversity is being lost at a rapid rate owing to anthropogenic causes, including habitat destruction, pollution and the spread of non-native species $[1,40]$. In this context, the main focus of this study was to understand how human activities (e.g. agricultural practices) in ecosystems could impact the diversity of PPN communities. The Mediterranean olive tree is particularly suitable for this study because it concerns ancient ecosystems with post-glacial refugia [16], many spots of Oleaster and many cases of feral olive. It also offers a large range of varieties, cultivated traditionally or at high-density, as present in Morocco.

\section{PPN diversity associated with olive trees in Morocco}

The PPN fauna and their distribution was totally unknown in Morocco before this study, except for a few reports on some nematodes such as root-knot nematodes Meloidogyne morocciensis [41] and cereal cyst nematodes [42]. This study clearly highlights a high taxonomical diversity of PPN communities where 117 species belonging to 47 genera were recorded. In addition, the study adds taxa (seven genera and 60 species) that were recorded for the first time in association with olive trees worldwide. The dominance pattern was also revealed by PCA analyses that demonstrated that the nematode dataset was mainly structured by the most frequent and abundant genera, and by less frequent but abundant nematodes to a lesser extent. The communities observed were mainly dominated by Filenchus and Helicotylenchus genera, and other nematodes such as Rotylenchus, Merlinius, Paratylenchus, Xiphinema, Pratylenchus and Tylenchorhynchus. Some of them have been previously reported as widespread on olive trees worldwide [15]. High population levels of some nematode genera such as root-knot nematodes (Meloidogyne spp.) and cyst nematodes (Heterodera spp.), considered as very dangerous soil-borne plant pests were also recorded [43].

The taxonomical diversity of PPN analyzed in Morocco is the greatest when compared to other surveys on olive trees that documented 223 species worldwide (reported in $[14,15,44-47])$. This high diversity and the detection of new taxa could be essentially explained by: (i) a large sampling effort (213 soil samples corresponding to 363 trees sampled), conducted along a long transect (about $900 \mathrm{~km}$ ) covering a wide range of olive-growing regions in Morocco; and (ii) a large proportion of samples collected in wild and feral olive areas (163 samples). These olive habitats could be considered as reservoirs of high diversity where a part remains unknown [48]. As evidence, a new root-knot nematode species, Meloidogyne spartelensis, was detected on wild olive in Northern Morocco [49]. However, other species could not be detected because they may occur only under unidentifiable life stages (e.g. juveniles), or their development may be linked to other periods of the year or to specific microhabitats [50]. As an example, no Rotylenchulus could be identified at the species level because all individuals were in the juvenile stage.

\section{Impact of anthropogenic changes on the PPN communities associated with olive trees in Morocco}

Taxonomical diversity indices were revealed impacted by olive propagation practices (from wild to cultivated olive): a high PPN richness was found in non-cultivated olive areas (wild and feral), with an equal distribution of species within communities (high evenness), contrary to what was observed in cultivated orchards (traditional and high-density). Nematode abundance was also significantly higher in orchards. A main conclusion also arose 


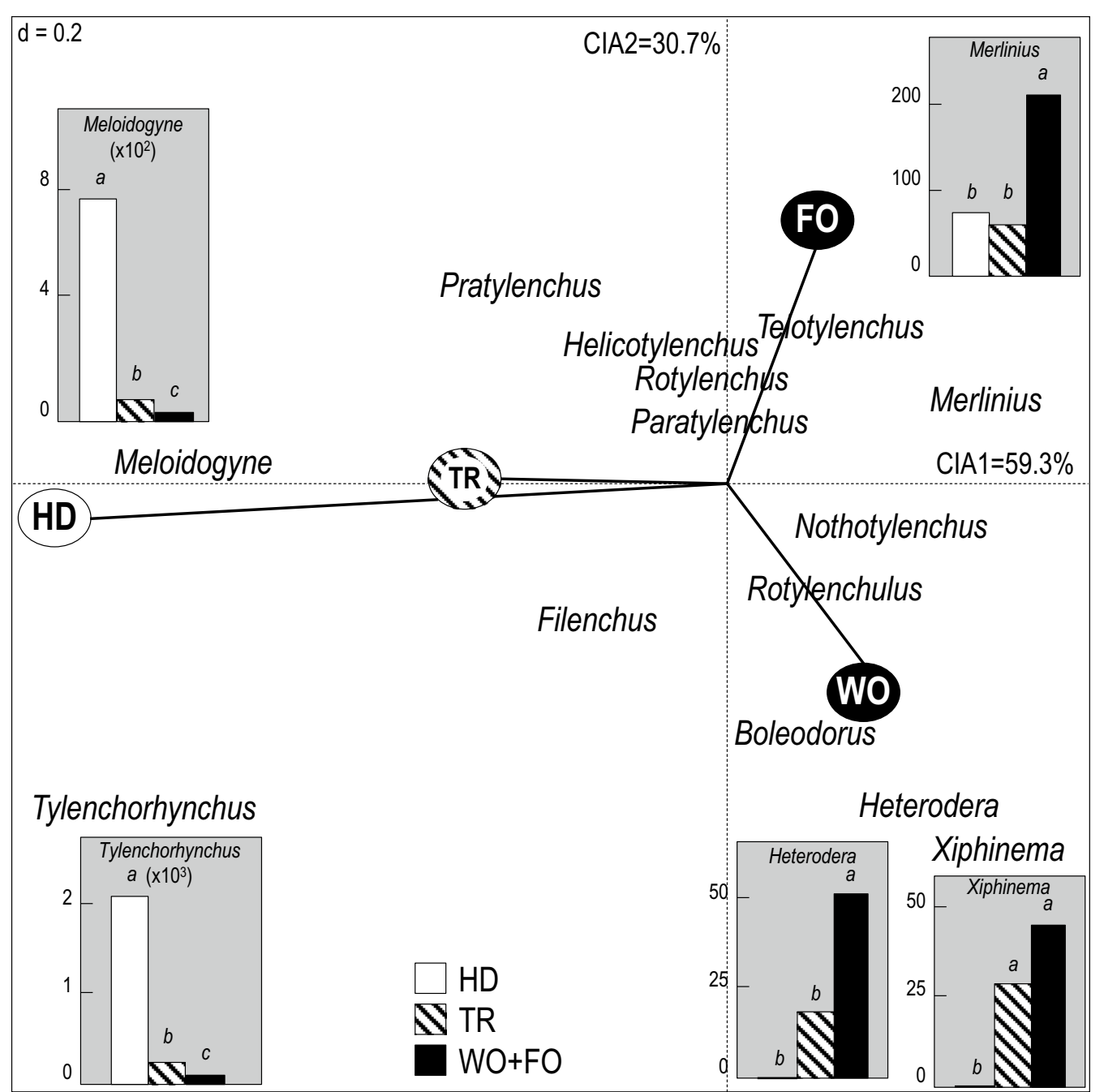

Fig. $3 \mathrm{CIA}$ loading plot for the nematode genera and the olive modalities. Histograms represent the mean comparisons of nematode abundances between olive-growing modality groups arranged according to their CIA1 eigenvalues. WO wild olive, FO feral olive, TR traditional cultivation, HD high-density cultivation

in this study that showed that PPN are abundant in cultivated conditions while richness, local diversity and evenness are low, and vice versa in non-cultivated conditions. In other words, a high PPN species diversity within a community may prevent the multiplication of the species as a potential effect of trade-off interactions between nematode species and/or between them and other soil microorganisms $[51,52]$.

The study also highlighted the impact of anthropogenic practices on the functional diversity in communities: persisters and fungal-feeders were more diverse and numerous in wild olive conditions, whereas colonizers were frequently present under high-density conditions. Colonizer nematodes were represented by fewer genera, confirming imbalance between the high relative abundance and the low-genus richness and vice versa. Moreover, $c p-5$ nematodes were particularly related to wild olive, and totally absent under high-density olive cultivation conditions. This is consistent with other studies that demonstrated that cultivation intensification usually does not reduce the number of nematode trophic groups, but may change the composition of these groups [53]. The taxonomical structures of the communities were also distinguished between wild and cultivated olive: genera such as Xiphinema and Heterodera were detected in relation to natural ecosystems (wild olive), while others (e.g. Meloidogyne and Tylenchorhynchus) were favoured in cultivated areas. Dominant taxa such as Helicotylenchus, Rotylenchus and Filenchus did not appear to be impacted, which could explain their high dominance in the samples. 
The taxonomical biodiversity indices were affected by the intensification level of farming systems between low or high tree-density orchards. The genus richness was usually higher in traditional than in high-density orchards. However, the intensification practices also impacted the functional diversity, as abundant $c p-2$ and FPF nematodes were found in traditional orchards, while $c p-3$ and OPF were more abundant in high-density olive orchards. The taxonomical structures of communities were also affected by olive cultivation intensification: genera such as Meloidogyne spp. and Tylenchorhynchus spp. were dominant in high-density orchards, whereas the traditional orchards were more favorable for the development of other genera such as Pratylenchus spp.

This study suggests that the PPN communities associated with non-cultivated olives (wild and feral) are not disturbed as a consequence of low or no human intervention in these ecosystems. This is consistent with other ecological observations that show that lowly-disturbed ecosystems generally host more diverse communities of soil organisms, as demonstrated for earthworms [54], for PPN [55] and for other soil biota communities [5, 6]. That is completely reversed in cultivated areas where the PPN communities were characterized by high abundances and low PPN's diversity. It is usually assumed that cropping systems are disturbed by human activities via agricultural practices (e.g. crop intensification, irrigation, tillage). These anthropogenic practices lead to species decline, as it has already been demonstrated on bees, birds and plants species [56], and soil biota $[5,6]$ including nematodes [57]. The decrease of nematodes diversity with increasing human activities can be attributed to several constraints such as physical disturbances, changes in quantity and quality of organic matter being returned to the soil and to the increase in the number of specific plant-feeding nematodes that are favoured by the selected crops [58].

These impacts on communities could be related to the biological characteristics of nematodes, leading them to respond differently to disturbances in their environment. These conditions induce favourable environments for PPN multiplication, especially irrigation, which enhances the development of roots [14]. This was consistent with others observations in southern Morocco [59]. This could explain the high abundance of colonizer species and, consequently, the high pathogenicity (PPI value) of the communities recorded in these cropping conditions. Moreover, agricultural practices applied in olive are very likely to select and multiply the most competitive and harmful PPN species such as Meloidogyne spp. in highdensity orchards. That could also explain the absence of persister species in these conditions, since they are very sensitive to environmental disturbances. That agrees with previous studies [53] showing that the greater $c p$-value nematodes are usually associated with low stress and undisturbed environments [9].

\section{Conclusion}

Anthropogenic changes such as propagation and intensification practices greatly impact the diversity of PPN communities associated with olive trees. Cultural practices (from wild to cultivated ecosystems or cropping intensification) could lead to community rearrangements in favour of highly pathogenic species defined as major agricultural pests [60]. In this vein, intensive production systems (high-yield varieties, irrigation, fertilization, etc.) induce environmental conditions suitable for the development of soil-borne diseases caused directly or indirectly (e.g. Verticillium wilt) by nematodes [14], such as root-knot (Meloidogynidae) and root-lesion (Pratylenchidae) nematodes. These groups of nematodes are known to affect olive production worldwide [15] and to be among the most frequent nematodes in nurseries [61]. Considering that the dispersal of PPN over long distances is passive (via contaminated irrigation, infected planting material or the dispersion of infested soil, etc. [30]), olive tree protection relies first on the use of healthy plant material (rootstocks) transplanted in a soil free of these parasites. The first step in avoiding PPN therefore starts in nurseries from where they could be introduced into olive orchards. This study also underlined PPN diversity and community structures as relevant indicators to assess resilient strategies in olive cropping systems. Further investigations should therefore focus on community rearrangements and on interactions between species co-existence mechanisms in order to develop diversity conservation or restoration (resilience) strategies [60] instead of reducing the most pathogenic species.

\section{Abbreviations \\ A: abundance; ade4: analyse de données écologiques version 4; ANOVA: analysis of variation; CIA: Co-inertia analysis; $C P$-value: a functional diversity index assigned to families of soil nematodes, which are categorized into a 1-5 colonizer-persister series; E: evenness; E1, E2, E3, M1, M2, M7: olive chloroplast lines; E1-1, E2-1, E3-4, M1-1, etc.: olive chloroplast haplotypes; F: frequency; FF: fungal feeders; FO: feral olive; FPF: facultative plant feeders; $\mathrm{H}^{\prime}$ : Shannon- Wiener diversity index; HD: high-density or modern cultivation; In: natural logarithm; N: total number of nematodes in a community; OPF: obligate plant feeders; PCA: principal component analysis; $p_{i}$ : proportion of individuals in each species i; PPI: plant-parasitic index; PPN: plant-parasitic nematodes; Rcp: relative mean abundance (\%) of each $c p$-value class in a community; S: species richness; SCAR: sequence characterized amplified region; TR: traditional or low-density cultivation; WO: wild olive.}

\section{Authors' contributions}

$N A, G B, B K, E C$ and TM designed the sampling device; NA, JT, GB, BK, MA, $M A H, A E M, A E O, A E B, A M, E C$ and TM acquired the field data; GB, BK, LE and AEB processed the olive genotyping; NA, JT and TM processed the nematode extraction from soils; NA, JT, ED, GW and TM carried out the morphological 
characterization of the nematode genera and species; NA and JT carried out the biochemical and molecular characterization of the root-knot nematode species; NA, JT, OFG and TM analyzed the data; NA, GB, OFG, EC and TM drafted the manuscript. All authors read and approved the final manuscript.

\section{Author details}

1 Plant Protection Department, Faculty of Agriculture, Tishreen University, PO Box 2233, Latakia, Syrian Arab Republic. ${ }^{2}$ IRD, UMR CBGP, 755 Avenue du Campus Agropolis, CS30016, 34988 Montferrier-sur-Lez Cedex, France. ${ }^{3}$ CNRS, UMR EDB, Université Toulouse III Paul Sabatier, Bâtiment 4R1, 118 Route de Narbonne, 31062 Toulouse Cedex 9, France. ${ }^{4}$ UMR AGAP, SUPAGRO, Campus CIRAD, TAA-108/03, Avenue Agropolis, 34398 Montpellier Cedex 5, France. ${ }^{5}$ Museum and Institute of Zoology PAS, Wilcza 64, 00-679 Warsaw, Poland. ${ }^{6}$ Faculté des Sciences et Techniques, Université Abdelmalek Essaadi, BP 2062, 93030 Tétouan, Morocco. ${ }^{7}$ Laboratoire LBVRN, Faculté des Sciences d'Agadir, Université Ibn Zohr, BP 8106, 80000 Agadir, Morocco. ${ }^{8}$ INRA, CRRA, BP 513, 40000 Marrakech, Morocco. ${ }^{9}$ INRA, UMR APCRPG, BP 578, 50000 Meknes, Morocco. ${ }^{10}$ IRD, UMR IPME (IRD/Université de Montpellier/CIRAD), 911 Avenue Agropolis, BP 64501, 34394 Montpellier Cedex 5, France. ${ }^{11}$ UMR PVBMT, 3P-CIRAD, 7 chemin de I'Irat, Ligne paradis, 97410 Saint Pierre, Réunion.

\section{Acknowledgements}

We would like to thank Simon Benateau (AgroCampus Ouest, Rennes, France) for his help in data analysis.

\section{Availability of data and materials}

The datasets during and/or analysed during the current study available from the corresponding author on reasonable request.

\section{Competing interests}

The authors declare that they have no competing interests.

\section{Funding}

This work was supported by a PhD grant from Tishreen University (Latakia, Syrian Arabic Republic). It was also funded by the PESTOLIVE project: Contribution of olive history for the management of soil-borne parasites in the Mediterranean Basin from EU and non-EU Mediterranean countries (ARIMNet action KBBE 219262) and by the LABEX entitled TULIP supported by the Agence Nationale de la Recherche (ANR-10-LABX-0041).

Received: 6 August 2016 Accepted: 16 December 2016 Published online: 06 February 2017

\section{References}

1. Chapin FS III, Zavaleta ES, Eviner VT, Naylor RL, Vitousek PM, Reynolds HL, Hooper DU, Lavorel S, Sala OE, Hobbie SE, Mack MC. Consequences of changing biodiversity. Nature. 2000;405:234-42.

2. Hooper DU, Chapin FS III, Ewel JJ, Hector A, Inchausti P, Lavorel S, Lawton JH, Lodge DM, Loreau M, Naeem S, Schmid B, Setälä H, Symstad AJ, Vandermeer J, Wardle DA. Effects of biodiversity on ecosystem functioning: a consensus of current knowledge. Ecol Monogr. 2005;75:3-35.

3. Giller PS. The diversity of soil communities, the'poor man's tropical rainforest'. Biodivers Conserv. 1996;5:135-68.

4. Vackár D, ten Brink B, Loh J, Baillie JE, Reyers B. Review of multispecies indices for monitoring human impacts on biodiversity. Ecol Indic. 2012;17:58-67.

5. Postma-Blaauw MB, de Goede RGM, Bloem J, Faber JH, Brussaard L. Soil biota community structure and abundance under agricultural intensification and extensification. Ecology. 2010;91:460-73.

6. Postma-Blaauw MB, de Goede RGM, Bloem J, Faber JH, Brussaard L. Agricultural intensification and de-intensification differentially affect taxonomic diversity of predatory mites, earthworms, enchytraeids, nematodes and bacteria. Appl Soil Ecol. 2012;57:39-49.

7. Pen-Mouratov S, Rakhimbaev M, Steinberger Y. Seasonal and spatial variation in nematode communities in a Negev desert ecosystem. J Nematol. 2003;35:157-66.

8. Yeates GW, Bongers T, De Goede RG, Freckman DW, Georgieva SS. Feeding habits in soil nematode families and genera-an outline for soil ecologists. J Nematol. 1993;25:315-31.
9. Bongers T, Ferris $\mathrm{H}$. Nematode community structure as a bioindicator in environmental monitoring. Trends Ecol Evol. 1999;14:224-8.

10. Djian-Caporalino C, Védie H, Arrufat A. Gestion des nématodes à galles: lutte conventionnelle et luttes alternatives. L'atout des plantes pièges. Phytoma. 2009;624:21-5.

11. Nicol JM, Turner SJ, Coyne DL, Den Nijs L, Hockland S, Maafi ZT. Current nematode threats to world agriculture. In: Genomics and molecular genetics of plant-nematode interactions. Springer: Netherlands; 2011. p. $21-43$.

12. Nico Al, Jiménez-Díaz RM, Castillo P. Host suitability of the olive cultivars Arbequina and Picual for plant-parasitic nematodes. J Nematol. 2003;35:29-34.

13. Koenning SR, Overstreet C, Noling JW, Donald PA, Becker JO, Fortnum BA. Survey of crop losses in response to phytoparasitic nematodes in the United States for 1994. J Nematol. 1999;31:587-618.

14. Castillo P, Nico Al, Navas-Cortés JA, Landa BB, Jiménez-Díaz RM, Vovlas N. Plant-parasitic nematodes attacking olive trees and their management. Plant Dis. 2010;94:148-62.

15. Ali N, Chapuis E, Tavoillot J, Mateille T. Plant-parasitic nematodes associated with olive tree (Olea europaea L.) with a focus on the Mediterranean Basin: a review. CR Biol. 2014;337:423-42.

16. Besnard G, Khadari B, Navascues M, Fernandez-Mazuecos M, El Bakkali A, Arrigo N, Baali-Cherif D, Brunini-Bronzini de Caraffa V, Santoni S, Vargas P, Savolainen $\mathrm{V}$. The complex history of the olive tree: from late quaternary diversification of Mediterranean lineages to primary domestication in the northern Levant. Proc Biol Sci. 2013;280:20122833.

17. Médail F, Quézel P, Besnard G, Khadari B. Systematics, ecology and phylogeographic significance of Olea europaea L. subsp. maroccana (Greuter \& Burdet) P. Vargas et al., a relictual olive tree in south-west Morocco. Bot J Linn Soc. 2001;137:249-66.

18. El Mouhtadi I, Agouzzal M, Guy F. L'olivier au Maroc. OCL. 2014;21:D203.

19. Allen HD, Randall RE, Amable GS, Devereux BJ. The impact of changing olive cultivation practices on the ground flora of olive groves in the Messara and Psiloritis regions, Crete, Greece. Land Degrad Dev. 2006;17:249-73.

20. Khadari B, Charafi J, Moukhli A, Ater M. Substantial genetic diversity in cultivated Moroccan olive despite a single major cultivar: a paradoxical situation evidenced by the use of SSR loci. Tree Genet Genome. 2008;4:213-21.

21. Cade P, Thioulouse J. Identification of soil factors that relate to plant parasitic nematode communities on tomato and yam in the French West Indies. Appl Soil Ecol. 1998;8:35-49.

22. Besnard G, Hernandez P, Khadari B, Dorado G, Savolainen V. Genomic profiling of plastid DNA variation in the Mediterranean olive tree. BMC Plant Biol. 2011;11:80.

23. Seinhorst JW. Modifications of the elutriation method for extracting nematodes from soil. Nematologica. 1962;8:117-28.

24. Merny G, Luc M. Les techniques d'évaluation des populations dans le sol. In: Lamotte M, Boulière F, editors. Problèmes d'écologie: l'échantillonnage des peuplements animaux dans les milieux terrestres, Masson. Paris; 1969. p. 257-92.

25. Mai WF, Mullin PG. Plant-parasitic nematodes. A pictorial key to genera, 5th ed. New-York: Cornell University Press; 1996.

26. De Grisse AT. Redescription ou modifications de quelques techniques utilisées dans l'étude des nématodes phytoparasites. Meded Fakulteit Landbouw Gent. 1969;34:351-69.

27. van Benzoijen J. Methods and techniques for nematology. Wageningen: Wageningen University; 2006.

28. Cobb NA. Notes on nemas Intra vitam color reactions in nemas. Contrib Sci Nematol. 1917:5:120-4.

29. Ali N, Tavoillot J, Chapuis E, Mateille T. Trend to explain the distribution of root-knot nematodes Meloidogyne spp. associated with olive trees in Morocco. Agric Ecosyst Environ. 2016;225:22-32.

30. Bongers T. The maturity index: an ecological measure of environmental disturbance based on nematode species composition. Oecologia. 1990;83:14-9.

31. Bongers T, Bongers M. Functional diversity of nematodes. Appl Soil Ecol. 1998;10:239-51.

32. Wasilewska L. Changes in the structure of the soil nematode community over long-term secondary grassland succession in drained fen peat. Appl Soil Ecol. 2006;32:165-79. 
33. Neher $\mathrm{D}$, Bongers $\mathrm{T}$, Ferris $\mathrm{H}$. Computation of nematode community indices. In: Society of nematologists workshop, vol. 2. Estes Park, Colorado; 2004. p. 1-33.

34. Fortuner R, Merny G. Les nématodes parasites des racines associés au riz en Basse-Casamance (Sénégal) et en Gambie. Cah ORSTOM Ser Biol. 1973;21:3-20.

35. Oksanen J, Blanchet FG, Friendly M, Kindt R, Legendre P, McGlinn D, Minchin PR, O'Hara RB, Simpson GL, Solymos P, Stevens MHH, Szoecs E, Wagner H. Vegan: community ecology package, version 2.3-5. 2016. http://CRAN.R-project.org/package=vegan. Accessed 7 Sept 2016.

36. Chessel D, Dufour AB, Thioulouse J. The ade 4 package -I- one-table methods. R News. 2004;4:5-10.

37. Dray S, Dufour AB. The ade4 package: implementing the duality diagram for ecologists. J Stat Softw. 2007;22:1-20.

38. R Core Team. R: a language and environment for statistical computing. Vienna: R Foundation for Statistical Computing; 2016. http://www.Rproject.org/.

39. Huston MA. Hidden treatments in ecological experiments: re-evaluating the ecosystem function of biodiversity. Oecologia. 1997;1 10:449-60.

40. Barnosky AD, Matzke N, Tomiya S, Wogan GO, Swartz B, Quental TB, Marshall C, McGuire JL, Lindsey EL, Maguire KC, Mersey B. Has the Earth's sixth mass extinction already arrived? Nature. 2011:471:51-7.

41. Rammah A, Hirschmann H. Meloidogyne morocciensis n. sp. (Meloidogyninae), a root-knot nematode from Morocco. J Nematol. 1990;22:279.

42. Mokrini F, Andaloussi FA, Alaoui Y, Troccoli A. Importance and distribution of the main cereal nematodes in Morocco. In: Cereal cyst nematodes: status, research and outlook. Proceedings of the first workshop of the international cereal cyst nematode initiative, Antalya, Turkey, 21-23 October; 2009. p. 45-50.

43. Jones JT, Haegeman A, Danchin EG, Gaur HS, Helder J, Jones MG, Kikuchi T, Manzanilla-López R, Palomares-Rius JE, Wesemael WM, Perry RN. Top 10 plant-parasitic nematodes in molecular plant pathology. Mol Plant Pathol. 2013;14:946-61.

44. Hashim Z. Distribution, pathogenicity and control of nematodes associated with olive. Fundam Appl Nematol. 1982;5:169-81.

45. Lamberti F, Vovlas N. Plant-parasitic nematodes associated with olive. EPPO Bull. 1993;23:481-8.

46. Sasanelli N. Olive-nematodes and their control. In: Ciancio A, Mukerji $\mathrm{KG}$, editors. Integrated management of fruit crops nematodes. Berlin: Springer; 2009. p. 275-315.

47. Palomares-Rius JE, Castillo P, Montes-Borrego M, Navas-Cortés JA, Landa BB. Soil properties and olive cultivar determine the structure and diversity of plant-parasitic nematode communities infesting olive orchards soils in southern Spain. PLoS ONE. 2015;10:e0116890.

48. Christensen $\mathrm{M}$, Emborg J. Biodiversity in natural versus managed forest in Denmark. For Ecol Manag. 1996:85:47-51.
49. Ali N, Tavoillot J, Mateille T, Chapuis E, Besnard G, El Bakkali A, Cantalapiedra-Navarrete C, Liébanas G, Castillo P, Palomares-Rius JE. A new root-knot nematode Meloidogyne spartelensis n. sp. (Nematoda: Meloidogynidae) in northern Morocco. Eur J Plant Pathol. 2015;143:25-42.

50. Hodda M, Stewart E, FitzGibbon F, Reid I, Longstaff BC, Packer I. Nematodes: useful indicators of soil conditions. Canberra: RIRDC (Rural Industries Research and Development Company); 1999.

51. Kneitel JM, Chase JM. Trade-offs in community ecology: linking spatial scales and species coexistence. Ecol Lett. 2004;7:69-80.

52. Piskiewicz AM, Duyts H, Van der Putten WH. Multiple species-specific controls of root-feeding nematodes in natural soils. Soil Biol Biochem. 2008:40:2729-35.

53. Van Eekeren N, Bommelé L, Bloem J, Schouten T, Rutgers M, de Goede R, Reheul D, Brussaard L. Soil biological quality after 36 years of ley-arable cropping, permanent grassland and permanent arable cropping. Appl Soil Ecol. 2008:40:432-46.

54. Fragoso C, Brown GG, Patrón JC, Blanchart E, Lavelle P, Pashanasi B, Senapati B, Kumar T. Agricultural intensification, soil biodiversity and agroecosystem function in the tropics: the role of earthworms. Appl Soil Ecol. 1997:6:17-35.

55. Cadet P. Gestion écologique des nématodes phytoparasites tropicaux. Cah Agric. 1998; 7:187-94

56. Yamaura Y, Royle JA, Shimada N, Asanuma S, Sato T, Taki H, Makino SI. Biodiversity of man-made open habitats in an underused country: a class of multispecies abundance models for count data. Biodivers Conserv. 2012;21:1365-80

57. Pan FJ, Xu YL, McLaughlin NB, Xue AG, Yu Q, Han XZ, Liu W, Zhan L, Zhao $D, L i C J$. Response of soil nematode community structure and diversity to long-term land use in the black soil region in China. Ecol Res. 2012;27:701-14.

58. Kimenju JW, Karanja NK, Mutua GK, Rimberia BM, Wachira PM. Nematode community structure as influenced by land use and intensity of cultivation. Trop Subtrop Agroecosyst. 2009;11:353-60.

59. Aitt-Hamza M, Ferji Z, Ali N, Tavoillot J, Chapuis E, El Oualkadi A, Moukhli A, Khadari B, Boubaker H, Lakhtar H, Roussos S, Mateille T, El Mousadik A. Plant-parasitic nematodes associated with olive in southern Morocco. Int J Agric Biol. 2015;17:719-26.

60. Mateille T, Cadet P, Fargette M. Control and management of plant-parasitic nematode communities in a soil conservation approach. In: Ciancio A, Mukerji KG, editors. Integrated management and biocontrol of vegetable and grain crops nematodes. Dordrecht: Springer; 2008. p. 79-97.

61. Nico Al, Rapoport HF, Jiménez-Díaz RM, Castillo P. Incidence and population density of plant-parasitic nematodes associated with olive planting stocks at nurseries in southern Spain. Plant Dis. 2002;86:1075-9.

\section{Submit your next manuscript to BioMed Central and we will help you at every step:}

- We accept pre-submission inquiries

- Our selector tool helps you to find the most relevant journal

- We provide round the clock customer support

- Convenient online submission

- Thorough peer review

- Inclusion in PubMed and all major indexing services

- Maximum visibility for your research

Submit your manuscript at www.biomedcentral.com/submit
BioMed Central 